Efficient and Selective Recovery of Trace Scandium by Inorganic Titanium Phosphate Ion-Exchangers from Leachates of Waste Bauxite Residue

\title{
Zhang, Wenzhong
}

2017-02-20

Zhang , W , Koivula , R , Wiikinkoski , E , Xu , J , Hietala , S , Lehto , J \& Harjula , R 2017 , ' Efficient and Selective Recovery of Trace Scandium by Inorganic Titanium Phosphate Ion-Exchangers from Leachates of Waste Bauxite Residue ' , ACS Sustainable Chemistry \& Engineering , vol. 5 , no. 4 , pp. 3103-3114 . https://doi.org/10.1021/acssuschemeng.6b02870

http://hdl.handle.net/10138/179107

https://doi.org/10.1021/acssuschemeng.6b02870

submittedVersion

Downloaded from Helda, University of Helsinki institutional repository.

This is an electronic reprint of the original article.

This reprint may differ from the original in pagination and typographic detail.

Please cite the original version. 


\section{Efficient and Selective Recovery of Trace Scandium by Inorganic Titanium Phosphate Ion-Exchangers from Leachates of Waste Bauxite Residue}

Wenzhong Zhang *†, Risto Koivula†, Elmo Wiikinkoski†, Junhua Xu†, Sami Hietalał, Jukka Lehto† and Risto Harjula ${ }^{+}$

† Laboratory of Radiochemistry, Department of Chemistry, P.O. Box 55, Fl-00014 University of Helsinki, Finland

‡ Laboratory of Polymer Chemistry, Department of Chemistry, P.O. Box 55, FI-00014 University of Helsinki, Finland

*Corresponding author, Email: Wenzhong.Zhang@helsinki.fi, Phone: +358 (0) 294150129.

\section{Abstract}

Bauxite residue $(\mathrm{BR})$ is an inevitable industrial waste generated through the classic Bayer extraction of alumina from bauxite minerals. It contains relatively significant amount of valuable rare earth elements, including scandium, and therefore we explored the suitability of trace scandium recovery from BR acid leachate by titanium phosphate (TiP) ion exchangers. Three kinds of TiP materials (amorphous TiP, $\alpha$-TiP and $\gamma$-TiP) were synthesized through fluorine-free precursors and characterized by chemical analysis, XRD, FE-SEM, FTIR, UV/Vis diffuse reflectance spectrometry, ${ }^{31}$ P MAS NMR, TGA and potentiometric titration. The $\mathrm{Sc}^{3+}$ exchange capacities were determined as $1.74,0.55$ and 0.22 meq $\mathrm{g}^{-1}$ for amorphous, $\alpha$ - and $\mathrm{y}^{-\mathrm{TiP}}$, respectively. Competition of major elements ( $\left.\mathrm{Fe}, \mathrm{Al}, \mathrm{Ca}\right)$ in $\mathrm{BR}$ leachate with Sc uptake was studied in batch experiments using binary equimolar mixtures, and the separation factors of Sc/Fe ${ }^{2+}, \mathrm{Sc} / \mathrm{Al}$ and Sc/Ca reach the magnitudes of 10 to 1000 on amorphous TiP. 
The high $\mathrm{Sc}^{3+}$ selectivity by amorphous $\mathrm{TiP}$ was suspected to be the matching of $\mathrm{Ti}^{4+}$ lattice radius with $\mathrm{Sc}^{3+}$ ionic radius (both $0.745 \AA$ A). Finally, the separation of trace scandium from the simulated BR leachate solution was demonstrated on an amorphous TiP column. The interference of $\mathrm{Fe}^{3+}$ has been partially resolved by on-column reduction using sodium sulphite. The optimized final eluate contained only Sc, Fe and Al. The concentration ratio of Sc/Fe can be increased by a factor of 8.8 and Sc/Al by 265 through a single cycle of chromatographic separation with a Sc recovery rate of $91.1 \%$.

\section{KEY WORDS}

Titanium phosphate; scandium recovery; ion exchange; bauxite residue. 


\section{LIST OF ABBREVIATIONS}

Amorphous titanium phosphate (am-TiP)

Bauxite residue (BR)

Field emission scanning electron microscopy (FE-SEM)

Fourier transformed infrared spectroscopy (FTIR)

Ion exchange capacity (IEC)

Magic-angle spinning nuclear magnetic resonance (MAS NMR)

Microwave plasma-atomic emission spectrometry (MP-AES)

Rare earth element (REE)

Separation factor (SF)

Thermogravimetric analysis (TGA)

Titanium phosphate (TiP)

X-ray diffraction (XRD) 


\section{INTRODUCTION}

Rare earth elements (REEs) play an increasingly vital role in modern material technology owing to their unique characteristics. ${ }^{1}$ Among all the REEs, scandium is exceptionally rare and expensive. ${ }^{2}$ On the supply side, it is not an unabundant element but is distributed in trace amounts alongside other mineral ores. It is only produced as a by-product of other metal production. ${ }^{3}$ On the consumer side, growing commercial application demands, including aluminium-scandium alloys, ${ }^{4}$ solid oxide fuel cells, ${ }^{5}$ etc., are now evidently inhibited by its low availability and high price. ${ }^{6}$ Consequently, finding an additional route to manufacture the REEs from secondary resources has become a research hotspot. ${ }^{7}$

Bauxite residue ( $\mathrm{BR}$, red mud) is continuously produced as an industrial waste in large quantities during the extraction of alumina from bauxite ores through the Bayer process. An estimated worldwide BR inventory of 4 billion tonnes in 2015 constitutes the legacy of more than 100 years of alumina production. ${ }^{8}$ However, its disposal remains a complicated task due to the extreme alkalinity ( $\mathrm{pH} 10-13)$ and sodicity. ${ }^{9}$ Historically, marine disposal, lagooning and dry stacking have been used, yet none of them has proven to be ideal. ${ }^{10}$ There is thus a need to investigate large-volume and economically viable utilization options. ${ }^{8}$ Typically, BR contains significant amounts of iron (hematite), silica (desilication product), calcium, aluminium (diaspore, boehmite and gibbsite) and titanium (rutile and perovskite) oxide minerals. ${ }^{11}$ Extensive efforts have already been directed to the recovery of these major elements ${ }^{8,12-14}$ as well as utilizing the remains for cement application. ${ }^{15}$ Ores with a scandium content of 20-50 $\mathrm{g} \mathrm{t}^{-1}$ are considered a scandium resource and deserve full exploitation, whereas the scandium concentration in some BR could reach 60-120 $\mathrm{g} \mathrm{t}^{-1}{ }^{16}$

Considering the vast amount of BR generated, the extraction of REEs, especially scandium, potentially adds value to the whole valorisation chain. The complete conceptual separation process 
for Sc from BR is illustrated in Scheme S1. To enable the extraction of REEs, they must be leached from BR. In a typical leaching process, BR is treated with mineral acid solutions to dissolve the REEs. ${ }^{17}$, 18 Inevitably, excess amount of sodium, calcium, aluminium, silica, titanium and iron ions are coleached with REEs into the leachate. The silica and titanium contents can be easily precipitated by addition of base without sacrificing the REEs. The recovery of highly diluted REEs (several ppm) from the acid $\mathrm{BR}$ leachate with high salt background ( $\mathrm{Na}, \mathrm{Ca}, \mathrm{Fe}, \mathrm{Al}$ at thousands of ppm) is still particularly challenging because of the selectivity requirements. Ion exchange and solvent extraction are two important processes for scandium recovery. ${ }^{19}$ Previously, ionic liquids, ${ }^{20}$ functionalized chitosan-silica bio-hybrid materials ${ }^{21}$ and activated carbons ${ }^{22}$ have been used for scandium recovery.

Inorganic ion exchangers with unique ion selectivity are a promising class of materials to this end. Insoluble acid salts of tetravalent metals have long been known for and extensively studied for their ion exchange behaviour. The presence of two types of functional groups, metal-OH and phosphoric acid groups, enables the material to exhibit amphoteric behavior. ${ }^{23}$ The protons within the phosphate groups are predominantly responsible for ion exchange capability. Titanium phosphate (TiP) materials were chosen for the current study as these materials have great acid stability enabling their use in the acid leaching solution. The oxygens in the $\mathrm{PO}_{4}{ }^{3-}$ tetrahedron can be shared in different ways with titanium in an octahedral configuration, giving rise to altered structural combinations such as amorphous, fibrous, layered or three-dimensional structures. ${ }^{24-26}$ Among these, the most investigated are amorphous TiP and lamellar-type layered $\alpha$-TiP and $\psi$-TiP. The ion selectivity of $\alpha$-TiP might arise from steric hindrance, where cations with a larger diameter are unable to be exchanged into the interlayer. ${ }^{27}$. The ionic potential and hydrolytic constant of metal ions were ascribed to dominantly affect the selectivity of metal ion exchange on $\alpha$-TiP. ${ }^{28}$ In addition, layered material also 
exhibits an excellent host structure for post-synthesis modification of the interlayer space. ${ }^{29}$

Chromatographic separation of inorganic ions has been achieved on crystalline TiP thin layers. ${ }^{30}$ To date, the ion exchange behaviour of TiP or similarly zirconium phosphate, has been systematically reported by Clearfield and Alberti. ${ }^{24,31}$ In addition, mesoporous ${ }^{32}$ and inorganic-organic composite ${ }^{33}$, ${ }^{34}$ TiP materials have been developed. However, little is known about their behaviour towards REE ions.

The aim of our work was to investigate the potential applicability of TiP ion exchangers in the separation of trace scandium/REEs from complex waste streams. This paper involves the synthesis of amorphous, layered $\alpha$ - and $\mathrm{\gamma}$-TiP materials. The as-synthesized TiPs were characterized by chemical analysis, X-ray diffraction (XRD), field emission scanning electron microscopy (FE-SEM), Fourier transform infrared spectroscopy (FTIR), UV/Vis diffuse reflectance spectrometry, solid state ${ }^{31} \mathrm{P}$ magicangel spinning (MAS) nuclear magnetic resonance (NMR), thermogravimetric analysis (TGA) and potentiometric titration. The uptake behaviour of scandium by the TiPs was studied in detail in a batch mode operation. The selectivity for scandium ion exchange from acidic solutions are assessed in binary equimolar solutions of scandium and other typical ions ( $\mathrm{Fe}, \mathrm{Al}, \mathrm{Ca}, \mathrm{Y}$ ) present in $\mathrm{BR}$ leachate. Finally, the efficient and selective ion exchange separation of tra ce scandium from a simulated BR leachate was demonstrated in a lab-scale amorphous TiP column.

\section{EXPERIMENTAL SECTION}

Chemicals. Titanium (IV) tetrachloride (>99.9\%), hydrochloric acid (>37\%), neodymium (III) nitrate hexahydrate (>99.9\%), dysprosium (III) nitrate hydrate (>99.9\%), yttrium (III) nitrate hexahydrate (>99.8\%) were purchased from Sigma-Aldrich (Helsinki, Finland). Lanthanum (III) nitrate hexahydrate 
(>99.9\%) and scandium oxide (>99.99\%) were acquired from Alfa Aesar (Helsinki, Finland). Cerium (III) chloride heptahydrate (>98.0\%) was purchased from Fluka (Vienna, Austria). Orthophosphoric acid (85\%) was obtained from VWR Chemicals (Helsinki, Finland). Sulfuric acid (95-97\%) was purchased from J.T. Baker (Pennsylvania, US). Calcium nitrate tetrahydrate, sodium sulphite heptahydrate, and aluminium nitrate nonahydrate were obtained from Riedel-de Haen GmbH (Seelze, Germany). All elemental ( $\mathrm{Al}, \mathrm{Ca}, \mathrm{Ce}, \mathrm{Dy}, \mathrm{Fe}, \mathrm{La}, \mathrm{Na}, \mathrm{Nd}, \mathrm{Sc}$, and Ti) single standard solutions (1000 mg L ${ }^{-1}$, PrimAgplus cert. ref. material) and nitric acid (SpA super purity, 67-69\%) were purchased from Romil (Cambridge, UK). Milli-Q water (Millipore) with the resistivity of $18.2 \mathrm{M} \Omega \mathrm{cm}$ was used throughout the experiments.

Synthesis of amorphous titanium phosphate (am-TiP). The precipitation method used for the synthesis of am-TiP was adapted from the literature. ${ }^{35}$ Briefly, $25 \mathrm{~g}$ of $\mathrm{TiCl}_{4}$ was added quickly to 415 $\mathrm{mL}$ of $2 \mathrm{M} \mathrm{HCl}$ solution in a fume hood under strong magnetic stirring (300 rpm) until it gave a totally transparent solution. The prepared solution was added drop-wise via a peristatic pump with silicone tubing into $400 \mathrm{~mL}$ of $1.25 \mathrm{M} \mathrm{H}_{3} \mathrm{PO}_{4}$ solution with stirring at $150 \mathrm{rpm}$. The resulting white solid was let stand in the mother solution for $24 \mathrm{~h}$ before filtering out and washing with water until a pH of 3.5 was attained and then air-dried at $70{ }^{\circ} \mathrm{C}$. All TiPs were ground and sieved to particle size of $74-149 \mu \mathrm{m}$ (100-200 mesh) before further study.

Synthesis of $\boldsymbol{\alpha}$-TiP. A HF-free hydrothermal synthesis method was us ed to synthesize $\alpha$-TiP. ${ }^{36}$ Ten millilitre of $\mathrm{TiCl}_{4}$ was added drop-wise into $50 \mathrm{~mL}$ of water with strong magnetic stirring (300 rpm) until it became transparent, and $40 \mathrm{~mL}$ of concentrated $\mathrm{H}_{3} \mathrm{PO}_{4}(85 \%)$ was added. The gel-like mixture was then sealed in a Teflon-lined stainless autoclave (filling ca. $60 \%$ of the Teflon cavity) and heated at 
$180{ }^{\circ} \mathrm{C}$ for $12 \mathrm{~h}$. The product was filtered, washed with water until a $\mathrm{pH}$ of 3.5 were reached and then air-dried at $70{ }^{\circ} \mathrm{C}$.

Synthesis of $\boldsymbol{\gamma}$-TiP. $\gamma$-TiP was synthesized by conversion from amorphous phase. ${ }^{37}$ Five grams of the as-synthesized am-TiP was placed in a Teflon container and $100 \mathrm{~mL}$ of concentrated $\mathrm{H}_{3} \mathrm{PO}_{4}$ was added. After stirring for $24 \mathrm{~h}$ at $300 \mathrm{rpm}$ the container was put inside a stainless autoclave and heated at $225{ }^{\circ} \mathrm{C}$ for $48 \mathrm{~h}$. The product was filtered out and washed completely with water until a pH of 3.5 was attained and then air-dried at $70{ }^{\circ} \mathrm{C}$.

Characterization of TiPs. The ratios of $\mathrm{PO}_{4} / \mathrm{Ti}$ were determined spectrometrically by dissolving weighed amount of the material in a mixture of sulphuric acid (98\%) and ammonium sulphate ${ }^{35}$ using a CEM MARS 5 microwave digestion system. Powder XRD patterns ( $2 \theta$ angle from 5 to $70^{\circ}$ ) of the TiPs were collected using a PANalytical X'Pert PW3710 MPD diffractometer coupled with a PW3020 vertical goniometer in Bragg-Brentano geometry. X-ray radiation was sourced from monochromatic CuK $\alpha$ line $(\lambda=1.54056 \AA)$ at $40 \mathrm{kV}$ and $40 \mathrm{~mA}$. Surface morphology of the TiPs was examined using a Hitachi S-4800 FE-SEM. Infrared spectra $\left(400-4000 \mathrm{~cm}^{-1}\right)$ were recorded on a Perkin Elmer Spectrum One FTIR spectrometer with a Universal ATR sampling accessory. UV/Vis diffuse reflectance spectra (200-800 nm) were collected on a Perkin Elmer Lambda 40 UV/Vis spectrometer equipped with a Labsphere RSA-PE-20 diffuse reflectance and transmittance accessory. Solid-state ${ }^{31}$ P MAS NMR spectra were obtained with a Bruker Avance III NMR spectrometer operating at $500 \mathrm{MHz}$ for protons. Samples were packed in $4 \mathrm{~mm} \mathrm{ZrO}_{2}$ rotors and spun at $12 \mathrm{kHz}$. Standard Bruker high power decoupling (hpdec) pulse sequence with proton decoupling was used for measurements. At least 512 transients for each sample were acquired using $7.22 \mu$ s pulse and $5 \mathrm{~s}$ recycle delay. The spectra were externally referenced to $85 \% \mathrm{H}_{3} \mathrm{PO}_{4}$. The line deconvolution of the acquired ${ }^{31} \mathrm{P}$ MAS NMR spectra is 
performed by OriginPro 8.6 using $100 \%$ Lorentzian peak. TGA was performed using a Mettler Toledo TGA/DSC 1 instrument under nitrogen atmosphere, $70 \mu \mathrm{L}$ alumina crucibles were used and the heating rate was set at $10^{\circ} \mathrm{C} \mathrm{min}^{-1}$.

Potentiometric titration. Potentiometric titration of the TiPs was performed according to reference method. ${ }^{38}$ Portions $(0.1 \mathrm{~g})$ of TiP materials were first equilibrated with $20 \mathrm{~mL}$ of water $\left(0.1 \mathrm{M} \mathrm{NaNO}_{3}\right)$ overnight on a rotary mixer $(50 \mathrm{rpm})$. The set of mixtures was then titrated with increasing amount ( 0.05 to $2 \mathrm{~mL}$ ) of $0.1 \mathrm{M} \mathrm{NaOH}$ solution in batch operation with an equilibrium time of 1 day. For determining the $\mathrm{Na}^{+}$exchange capacities, $0.1 \mathrm{~g}$ of TiPs was mixed with $10 \mathrm{~mL}$ of $0.25 \mathrm{M}$ $\mathrm{Na}_{2} \mathrm{CO}_{3}$ solution on a rotary mixer until equilibrium is reached. The $\mathrm{Na}^{+}$concentrations before and after sorption were measured by an Agilent 4100 MP-AES (microwave plasma-atomic emission spectrometry) system.

Theory of ion exchange. Considering the binary ion exchange between aqueous $\mathrm{M}^{\mathrm{n}+}$ and $\mathrm{H}^{+}$in TiP materials, the reaction can be expressed as

$$
M^{n+}+n \bar{H}^{+} \leftrightarrow \bar{M}^{n+}+n H^{+}
$$

where the barred symbols refer to the ions in the solid TiP materials.

The distribution coefficient $\left(K_{\mathrm{d}}, \mathrm{mL} \mathrm{g}^{-1}\right)$ demonstrates the distribution of the element (e.g. Sc) within the equilibrium solution and solid material calculated by the following equation:

$$
K_{d}=\frac{\left[M^{n+}\right]_{e q .}}{\left[M^{n+}\right]_{e q .}}=\frac{\left[M^{n+}\right]_{i .}-\left[M^{n+}\right]_{e q .}}{\left[M^{n+}\right]_{e q .}} \times \frac{V}{m}
$$


where $\left[\overline{M^{n+}}\right]_{e q .}$ is the equilibrium metal concentration in the solid, $\left[M^{n+}\right]_{i .}$ and $\left[M^{n+}\right]_{e q}$. are respectively the metal concentration of the solution at initial and equilibrium states $\left(\mathrm{mg} \mathrm{L}^{-1}\right), V$ is the volume of the solution $(\mathrm{mL})$ and $m$ is the mass of the TiP material $(\mathrm{g})$.

The ion exchange reaction stoichiometry can be calculated using the $\mathrm{pH}$ and metal concentration variations before and after the equilibrium. The following equation describes the ratio of $\mathrm{H}^{+}$to $\mathrm{M}^{\mathrm{n}+}$ :

$$
H^{+} / M^{n+}=\frac{\Delta\left[H^{+}\right]}{\Delta\left[M^{n+}\right]}=\frac{10^{-p H e q \cdot-10^{-p H_{i}}}}{\left[M^{n+}\right]_{i .}-\left[M^{n+}\right]_{e q}}
$$

where $\mathrm{pH}_{\mathrm{i}}$ and $\mathrm{pH}_{\text {eq. }}$ are respectively the initial and equilibrium solution $\mathrm{pH}$. The value of $\mathrm{H}^{+} / \mathrm{M}^{\mathrm{n}+}$ should equal $n$ if the exchanged ions exist in unhydrolysed form within the ion exchangers.

Batch ion exchange experiments. Typically, $100( \pm 1) \mathrm{mg}$ of TiP was placed in a polyethylene vial with $20 \mathrm{~mL}$ of test solution. Samples were equilibrated for 3 days on a constant rotary mixer (50 rpm). The solid/liquid separation was then achieved by centrifugation (15 $\mathrm{min}$ at $3000 \mathrm{~g}$ ), and adequate amount of the supernatant was pipetted out for concentration determination. Equilibrium $\mathrm{pH}$ was measured from the remaining solution and, when necessary, the solid phase was dried and kept for characterization. The separation factor (SF) between metal ions $M_{1}$ and $M_{2}$ was subsequently calculated based on their $K_{d}$ values:

$$
S F_{M_{1} / M_{2}}=\frac{K_{d}\left(M_{1}\right)}{K_{d}\left(M_{2}\right)} \quad \text { (Eq. 4) }
$$

Binary systems (prepared by metal nitrate salts) comprising of $1 \mathrm{mM}$ equimolar mixture of scandium and one of the competing ions $(\mathrm{Al}, \mathrm{Ca}, \mathrm{Fe}, \mathrm{La}, \mathrm{Y})$ present in the acid leachate of BR were studied as a function of $\mathrm{pH}$ in the range of 1 to 5 . The $\mathrm{pH}$ was adjusted with $\mathrm{HNO}_{3}$ or $\mathrm{NaOH}\left(\mathrm{Na}^{+}\right.$at low 
concentration have limited effect on the ion exchange of multivalent elements because of its low ability to form a $\pi$-bond). ${ }^{39}$ In the case of $\mathrm{Fe}$, instead of the $\mathrm{Fe}^{3+}$, which starts to precipitate around $\mathrm{pH}$ 2 at $1 \mathrm{mM}$ concentration, $\mathrm{Fe}^{2+}$ was studied in the $\mathrm{pH}$ range of 1 to 5 . Iron(II) sulphate was used to prepare the $\mathrm{Fe}^{2+}$ solution and $0.05 \mathrm{M}$ of $\mathrm{Na}_{2} \mathrm{SO}_{3}$ was added to the solution to maintain the reducing environment.

The scandium ion exchange isotherms of the TiP materials were determined at $\mathrm{pH} 2$ with the initial scandium concentration range of $1-500 \mathrm{mg} \mathrm{L}^{-1}\left(0.022-11.1 \mathrm{mmol} \mathrm{L}^{-1}\right)$.

Determination of the metals was performed by MP-AES. A pre-optimized amount of ionization suppressor (cesium nitrate) was added to the sample before analysis. Atomic emission lines were prioritized and possible spectrum interferences were minimized. External calibration methods were used in most cases with corresponding matrix matching, while for some high matrix sample a standard addition method was employed.

Batch elution study. Batch elution was conducted by first loading the TiP materials with metals at appropriate equilibrium $\mathrm{pH}$. After loading equilibrium was reached, the supernatant was decanted. The remaining material was quickly washed three times with $20 \mathrm{~mL}$ of water using centrifugation and re-dispersion, and the supernatants were all discarded. The acquired slurry was dried in an oven at $70{ }^{\circ} \mathrm{C}$ to evaporate all of the solution. After that, $20 \mathrm{~mL}$ of acid solution was introduced into the tube and samples were again equilibrated for 3 days. Finally, after centrifugation, an adequate amount of the supernatant was taken for metal concentration analysis. The acid used here were nitric acid, sulfuric acid, hydrochloric acid and phosphoric acid at concentrations of $0.1,0.2,0.5,1.0$ and 2.0 M. 
Two systems of initial loading solution were studied: $1 \mathrm{mM} \mathrm{Sc}$ and $1 \mathrm{mM}$ equimolar mixture of $\mathrm{Ca}, \mathrm{Al}$ and Fe (II). The $K_{\mathrm{d}}\left(\mathrm{mg} \mathrm{L}^{-1}\right)$ values of the elution systems were calculated as follows:

$$
K_{d}=\frac{q_{\text {eq. }}}{c_{\text {elu.eq. }}}=\frac{q_{\text {uptake }}-c_{\text {elu.eq }} \times \frac{V}{m}}{c_{\text {elu.eq. }}}
$$

where $q_{\text {uptake }}$ and $q_{\text {eq. }}$ are the amount of metal uptake and elution (meq $\mathrm{g}^{-1}$ ) and $c$ elu.eq. is the equilibrium concentration of metal in the elution acid $\left(e q L^{-1}\right)$.

Column separation using simulated BR leachate. Lab-scale column, with an inner diameter of $1 \mathrm{~cm}$, was packed with $1.0 \mathrm{~g}$ of am-TiP material. The height of the column was approximately $4.7 \mathrm{~cm}$. The recipe of simulated $B R$ leachate $(\mathrm{pH} 2)$ was derived from a report by Roosen ${ }^{21}$ and contained 1100 ppm (47.9 mmol L-1) of $\mathrm{Na}, 1000 \mathrm{ppm}\left(25.0 \mathrm{mmol} \mathrm{L}^{-1}\right)$ of $\mathrm{Ca}, 700 \mathrm{ppm}\left(25.9 \mathrm{mmol} \mathrm{L}^{-1}\right)$ of Al, $110 \mathrm{ppm}$ (1.97 mmol L-1) of Fe(III), 600 ppm (21.4 mmol L-1) of Si, 110 ppm (2.30 mmol L-1) of Ti(IV), 2 ppm (0.044 $\left.\mathrm{mmol} \mathrm{L}^{-1}\right)$ of Sc and $6 \mathrm{ppm}\left(0.043 \mathrm{mmol} \mathrm{L}^{-1}\right)$ of La (representing all lanthanides). After loading the column with simulated BR leachate, on-column reduction of $\mathrm{Fe}^{3+}$ was performed by eluting with 2 bed volumes $(\mathrm{BV})$ of $0.05 \mathrm{M}$ sodium sulfite solution at $\mathrm{pH} 2$. The column was soaked with the reductant overnight and then further rinsed by eluting with 2 BV of water before the elution process. The eluents used were $0.2 \mathrm{M}$ nitric acid, $0.3 \mathrm{M}$ nitric acid and a mixed acid consisting of $0.5 \mathrm{M}$ nitric acid and $0.5 \mathrm{M}$ phosphoric acid. Both loading and elution flow rates were set at $1 \mathrm{BV} \mathrm{h}^{-1}$. A Teledyne ISCO Retriever 500 fraction collector with a time interval of 60 or 120 min collected the effluent before MP-AES analysis.

Reusability test. The reusability of the am-TiP material (100 mg) was studied by repeated sorptionelution cycles in a batch mode. The loading solution was $20 \mathrm{~mL}$ of $1 \mathrm{mM}$ equimolar mixture of Sc and 
Al at $\mathrm{pH}$ 4.0. The elution was done by $20 \mathrm{~mL}$ of $0.5 \mathrm{M}$ equimolar mixture of nitric acid and phosphoric acid. Altogether five cycles were performed. The Sc uptake and $\mathrm{SF}(\mathrm{Sc} / \mathrm{Al})$ in each cycle were calculated.

\section{RESULTS AND DISCUSSION}

Characteristics of TiPs. Three types of synthesized TiPs were characterized using chemical analysis, XRD, FE-SEM, FTIR, UV/Vis diffuse reflectance spectrometry, solid state ${ }^{31} \mathrm{P}$ MAS NMR, TGA and potentiometric titration. Chemical analysis showed that the molar $\mathrm{PO}_{4} /$ Ti ratios are $1.02 \pm 0.01,1.97 \pm$ 0.04 and $1.98 \pm 0.03$ for am-, $\alpha$ - and $\gamma$-TiP, respectively. Within the range of uncertainty, the $\mathrm{PO}_{4} / \mathrm{Ti}$ ratios in $\alpha$ - and $\psi$-TiP equal with the ideal value of 2 . The $\mathrm{PO}_{4} / \mathrm{Ti}$ ratio of am-TiP was rounded up to 1 for the following calculations. Their crystal phases were identified by powder XRD and are shown in Fig. 1. Am-TiP presented no sharp diffraction peaks, only a very broad one at $20-30^{\circ}$, indicating its amorphous nature. The patterns obtained for $\alpha$ - and $\gamma$-TiP agree well with references (JCPDS card no. 44-382 and García-Granda ${ }^{40}$ ) and the corresponding Miller indices are indicated in the figure. Two peaks indicated with an asterisk in the $\mathrm{\gamma}$-TiP sample are attributed to the dehydrated form (with no crystal water), ${ }^{37}$ probably due to the drying condition in our study at $70^{\circ} \mathrm{C}$. The interlayer spacing $d$ calculated from the XRD data gave $7.60 \AA$ for $\alpha$-TiP and $11.59 \AA$ for $\psi$-TiP, which are characteristic for both crystalline materials. Product morphologies of the TiPs were observed by FE-SEM (Fig. 2). Am-TiP exhibited rock-like structure with irregularly shaped bulk parts, whereas lamellar TiPs showed ordered crystal structures. The stacked pellets of $\alpha$ - and $y$-TiP are clearly observable from Fig. 2 ( $d$ and $f$ ). Size of the $\alpha$-TiP crystals was smaller than that of the $\psi$-counterpart under current synthesis conditions.

Fig. S1 shows the infrared spectra of the synthesized materials. Generally, peaks at around $1600 \mathrm{~cm}^{-1}$ are caused by the lattice water and peaks at $900-1300 \mathrm{~cm}^{-1}$ are assigned to the symmetrical 
and asymmetrical stretching vibration of $\mathrm{PO}_{3} \cdot{ }^{36,41}$ Different modes of free surface $-\mathrm{OH}$ symmetrical stretching band of the P-OH group ${ }^{28}$ were observed in $\alpha$ - and $\gamma$-TiP: at 3553 and $3477 \mathrm{~cm}^{-1}$ in $\alpha$-TiP and at $3220 \mathrm{~cm}^{-1}$ in $\gamma^{-T i P}$. This indicates that the microenvironment of the phosphate group in two types of lamellar materials are different, which could give rise to varying metal affinity. ${ }^{24}$ The vibrations of Ti-O bonds and lattices are not detectable under IR range. ${ }^{41}$ The UV/Vis spectra of the TiP materials (Fig. S2) exhibited the characteristic absorption band of intra-framework tetrahedrally coordinated $\mathrm{Ti}$ at around $200 \mathrm{~nm} .^{28}$ The absence of absorption peaks ranging from 310 to $350 \mathrm{~nm}$ suggests that no trace amounts of anatase $\left(\mathrm{TiO}_{2}\right)$ was mixed into the TiP materials.

In order to fully understand the existence state of the phosphate groups within different TiP materials, ${ }^{31}$ P MAS NMR was performed (Fig. 3). The phosphorus in am-TiP exists mainly in the form of $\mathrm{H}_{2} \mathrm{PO}_{4}$ groups (peak at $-7.2 \mathrm{ppm}$ ) and partly as $\mathrm{HPO}_{4}$ groups (shoulder at $-15.9 \mathrm{ppm}$ ), ${ }^{23}$ here two-line deconvolution was found to be a better fit than three-line deconvolution. The estimated ratio between $\mathrm{H}_{2} \mathrm{PO}_{4}$ and $\mathrm{HPO}_{4}$ groups is about 4:1 (3.97:1 to be exact) based on the intensity of the two resonances. $\alpha$-TiP shows a single narrow resonance at $-18.1 \mathrm{ppm}$, suggesting only $\mathrm{HPO}_{4}$ groups are present. ${ }^{42}$ On the other hand, $\mathrm{Y}$-TiP exhibits four resonances. The peaks at -10.6 and -32.5 ppm are assigned to fully hydrated form $\left[\mathrm{Ti}\left(\mathrm{PO}_{4}\right)\left(\mathrm{H}_{2} \mathrm{PO}_{4}\right) \cdot 2 \mathrm{H}_{2} \mathrm{O}\right.$, with two crystal water] and the peaks at -15.2 and -29.8 ppm corresponds to fully dehydrated form $\left[\mathrm{Ti}\left(\mathrm{PO}_{4}\right)\left(\mathrm{H}_{2} \mathrm{PO}_{4}\right)\right] .{ }^{43}$ This indicates that the synthesized ' $\gamma$-TiP' is a mixture of fully hydrated and fully dehydrated $\mathrm{Ti}\left(\mathrm{PO}_{4}\right)\left(\mathrm{H}_{2} \mathrm{PO}_{4}\right)$, no partially dehydrated form is observed. According to the line deconvolution results, the ratio of fully hydrated to fully dehydrated form is 1.4 (Table S1). Free water may also present in the material therefore the average formula is calculated later based on the TGA results. 
Upon heating in an inert atmosphere, dehydration and dehydroylation reactions occur within the TiP materials (Fig. 4). The free water and crystal water are lost in the initial stage, and under higher temperature the hydroxyl condensation occurs, leading to the formation of pyrophosphate. In the case of am-TiP, all these processes are overlapped considerably and some of them occur simultaneously. ${ }^{23}$ To obtain the formula of am-TiP and understand its pyrolytic process, additional studies were performed. The sulphate ion uptake capacity of the am-TiP was determined to be 3.17 meq g-1 in $0.05 \mathrm{M} \mathrm{H}_{2} \mathrm{SO}_{4}-\mathrm{Na}_{2} \mathrm{SO}_{4}$ system. The XRD pattern (Fig. S3) of the am-TiP treated at $1000{ }^{\circ} \mathrm{C}$ shows only pyrophosphate $\mathrm{Ti}_{2} \mathrm{O}\left(\mathrm{PO}_{4}\right)_{2}$ or $(\mathrm{TiO})_{2} \mathrm{P}_{2} \mathrm{O}_{7}$ phase without any $\mathrm{TiO}_{2}$ present. The two pyrophosphate isomers are indistinguishable by XRD. It is known that $\mathrm{Ti}_{2} \mathrm{O}\left(\mathrm{PO}_{4}\right)_{2}$ transforms to (TiO) ${ }_{2} \mathrm{P}_{2} \mathrm{O}_{7}$ phases at 700 to $1000{ }^{\circ} \mathrm{C}$ with no weight loss. ${ }^{26}$ Combined with the Ti and $\mathrm{P}$ contents obtained from chemical analysis (correspondingly $25.36 \%$ and $16.73 \%$ ), the composition of our am-TiP was identified as $\mathrm{TiO}_{1.11}(\mathrm{OH})_{0.58}\left(\mathrm{HPO}_{4}\right)_{0.2}\left(\mathrm{H}_{2} \mathrm{PO}_{4}\right)_{0.8} \cdot 0.64 \mathrm{H}_{2} \mathrm{O}$, which is a hydrous titanium oxohydroxyphosphate material. Its overall thermal decomposition with theoretical weight loss of $17.94 \%$ can be expressed by the following equation:

$$
\begin{gathered}
2 \mathrm{TiO}_{1.11}(\mathrm{OH})_{0.58}\left(\mathrm{HPO}_{4}\right)_{0.2}\left(\mathrm{H}_{2} \mathrm{PO}_{4}\right)_{0.8} \cdot 0.64 \mathrm{H}_{2} \mathrm{O} \stackrel{-2.66 \mathrm{H}_{2} \mathrm{O}\left(\mathrm{RT}-300^{\circ} \mathrm{C}\right)}{\longrightarrow} 2 \mathrm{TiO}\left(\mathrm{HPO}_{4}\right) \\
\stackrel{-1 \mathrm{H}_{2} \mathrm{O}\left(300-700^{\circ} \mathrm{C}\right)}{\longrightarrow} \mathrm{Ti}_{2} \mathrm{O}\left(\mathrm{PO}_{4}\right)_{2} \stackrel{\left(700-1000^{\circ} \mathrm{C}\right)}{\longrightarrow}(\mathrm{TiO})_{2} \mathrm{P}_{2} \mathrm{O}_{7}
\end{gathered}
$$

The thermal behaviour of $\alpha$-TiP agreed well with its classic formula Ti(HPO $\left.{ }_{2}\right)_{2} \cdot \mathrm{H}_{2} \mathrm{O}$, while our so-called ' $\gamma$-TiP' after drying have an average formula of $\mathrm{Ti}\left(\mathrm{PO}_{4}\right)\left(\mathrm{H}_{2} \mathrm{PO}_{4}\right) \cdot 0.96 \mathrm{H}_{2} \mathrm{O}$. The ' $\mathrm{Y}$ - $\mathrm{TiP}$ ' used in the article all refers to the mixed material with y type layered structure without emphasizing the amount of crystal water. 
Potentiometric titration (both with and without salt addition) was performed to confirm the existence states of phosphate groups (Fig. 5) and the total ion exchange capacity (IEC) of the TiPs were determined by titration without added salt and by measuring $\mathrm{Na}^{+}$uptake. The total IEC corresponds to the amount of $\mathrm{Na}^{+}$ions added before reaching the plateau in the titration curves (without salt addition). ${ }^{45}$ The am-TiP exhibited steadily increasing titration curve, thereby confirming its amorphous nature. It is noted that in the titration curve of am-TiP without added salt, one inflection point at $\mathrm{pH} 4$ can be observed, probably due to the first proton dissociation from $\mathrm{H}_{2} \mathrm{PO}_{4}$ or $\mathrm{HPO}_{4}$ group. The total IEC estimated by titration curve is $5.6 \mathrm{meq} \mathrm{g}^{-1}$, while the same by $\mathrm{Na}_{2} \mathrm{CO}_{3}$ sorption equals to $5.13 \mathrm{meq} \mathrm{g}^{-1}$. The $\mathrm{Na}^{+}$IEC account for $52.4-57.2 \%$ of its total formula-calculated IEC (9.79 meq $\left.\mathrm{g}^{-1}\right)$. The titration curves of the layered TiPs showed single- and di-protonic behaviour with clearly visible $\mathrm{pH}$ plateaus and inflection points between them. The $\mathrm{p} K_{\mathrm{a}}$ values were chosen from the midpoint of the $\mathrm{pH}$ plateaus. Titration without added salt gives directly the $\mathrm{pKa}$ values, and for titration with $0.1 \mathrm{M} \mathrm{NaNO}_{3}$ background, the $\mathrm{pKa}$ values are only apparent values. The apparent $\mathrm{p} K_{\mathrm{a}}$ values cannot be directly compared with the $\mathrm{p} K_{\mathrm{a}}$ values of dissolved phosphoric acids because the former is strongly dependent on the added salt concentration in the titration system. ${ }^{46}$ The IECs and chemical formulae of the TiPs are summarized in Table 1. The $\mathrm{Na}^{+}$IEC from batch sorption of $\mathrm{Na}_{2} \mathrm{CO}_{3}$ solution agreed well with the titration data of both approaches. The $\mathrm{p} K_{\mathrm{a}}$ values of layered TiPs could be rationalized by their chemical formulae, with $\alpha$-TiP accommodating two identical $\mathrm{HPO}_{4}$ groups and $\gamma$-TiP harbouring two types of $\mathrm{P}$-containing groups $\left(\mathrm{PO}_{4}\right.$ and $\left.\mathrm{H}_{2} \mathrm{PO}_{4}\right) .{ }^{44}$ The two $\mathrm{p} K_{a}$ values of $\gamma$-TiP are due to the stepwise release of two protons in $\mathrm{H}_{2} \mathrm{PO}_{4}$ group. Note that the actual pKa value of $\alpha$-TiP might be lower than 4.1 since the ion exchange can occur at lower $\mathrm{pH}$ compared to the starting point 
of the titration. The $\mathrm{pKa}$ values of $\mathrm{\gamma}-\mathrm{TiP}\left(\mathrm{p} K_{\mathrm{a} 1}=2.5, \mathrm{p} K_{\mathrm{a} 2}=7.0\right)$ are reasonably close to that of phosphoric $\operatorname{acid}\left(\mathrm{p} K_{\mathrm{a} 1}=2.14, \mathrm{p} K_{\mathrm{a} 2}=7.20\right)$

Effect of equilibrium pH on scandium ion exchange behaviours. The substitution of hydronium in TiPs with aqueous metal cations is essentially responsible for the ion exchange capability of the TiP materials. The solution $\mathrm{pH}$ is expected to have a predominant effect on the ion exchange behaviours. Fig. 6 demonstrates the effects of solution equilibrium $\mathrm{pH}$ on the $\mathrm{Sc}^{3+}$ ion uptake values in TiPs. Theoretically, the continuing increase of metal uptake with rising $\mathrm{pH}$ should be observed, until the accessible ion exchange sites of the material are saturated. This was indeed the case in $\alpha$ - and $\gamma$-TiP. The plateaus of uptake value were reached at around $\mathrm{pH} 2$ and no significant uptake increase was observed at $\mathrm{pH} 2$ to 3.5. The studied $\mathrm{pH}$ range was kept below 4.5 to avoid Sc precipitation. For $\alpha$-TiP, a steady increase of uptake starting from $\mathrm{pH} 4$ was observed. In $\mathrm{\gamma}$-TiP, the second acidic sites ( $\mathrm{p} K_{a 2}$ 5.5) were still unavailable at the studied $\mathrm{pH}$ range. Considering am-TiP, the $\mathrm{pH}$-uptake curve is different from those of the crystalline materials; there was first a rapid uptake increase from $\mathrm{pH} 1$ to 2 , then a decrease until $\mathrm{pH} 3$, with the uptake remained the same value thereafter. The hydrolytic chemistry of $\mathrm{Sc}^{3+}$ is taken into account when justifying the curve. In acidic solution, $\mathrm{Sc}^{3+}$ hydrolyses to form mainly $\mathrm{Sc}(\mathrm{OH})^{2+}$ and polymeric $\mathrm{Sc}_{2}(\mathrm{OH})_{2}{ }^{4+} \cdot{ }^{47}$ According to related calculations, $\mathrm{Sc}(\mathrm{OH})^{2+}$ starts to form from $\mathrm{pH} 2$ and $\mathrm{Sc}_{2}(\mathrm{OH})_{2}{ }^{4+}$ from $\mathrm{pH} 3$ at the tested concentration. Although factors including hydrolytic constants of the metal ions affect the sequence of ion exchange selectivity, in principle, ion exchangers (such as TiP materials) have higher affinity towards cations of higher charges because of their higher ionic potentials. ${ }^{28}$ The divalent hydrolysed product $\mathrm{Sc}(\mathrm{OH})^{2+}$ may remain in solution and compete with the ion exchange reaction, leading to the uptake decrease from $\mathrm{pH} 2$ to 3 . The co-effect 
of increased polymerized tetravalent $\mathrm{Sc}_{2}(\mathrm{OH})_{2}{ }^{4+}$ and decreased divalent $\mathrm{Sc}(\mathrm{OH})^{2+}$ concentration resulted in the virtually unchanged uptake capacity from $\mathrm{pH} 3$ to 4 .

Separation factors in binary equimolar mixtures. Excess amounts of major metal ions, namely $\mathrm{Al}^{3+}$, $\mathrm{Fe}^{3+}, \mathrm{Ca}^{2+}, \mathrm{Si}^{4+}, \mathrm{Ti}^{4+}$ and $\mathrm{Na}^{+}$, are present in the acid $\mathrm{BR}$ leaching solution. $\mathrm{Ti}^{4+}$ and $\mathrm{Si}^{4+}$ do not cause much trouble since they can be easily precipitated at around $\mathrm{pH} 2$ without sacrificing the Sc and REE content. Monovalent and divalent ions have lower affinity towards the TiPs than trivalent $\mathrm{Sc}^{3+}$ and are therefore tolerable even at very high concentrations (thousands of ppm)..$^{39}$ The biggest challenge for separation of $\mathrm{Sc}^{3+}$ arises from the trivalent ions, es pecially $\mathrm{Fe}^{3+}$, which shares chemical similarities with $\mathrm{Sc}^{3+} \cdot{ }^{21}$ The elimination of $\mathrm{Fe}^{3+}$ is not possible through precipitation due to the occurrence of scandium co-precipitation. Notably, one approach for eliminating the interference of $\mathrm{Fe}^{3+}$ is to reduce it to $\mathrm{Fe}^{2+}$. Direct reduction of $\mathrm{Fe}^{3+}$ in the leaching solution is not possible in an economically viable and eco-friendly manner. In this paper, on-column reduction of $\mathrm{Fe}^{3+}$ was used for efficient separation of $\mathrm{Fe}^{3+}$ and $\mathrm{Sc}^{3+}$, as will be later seen. Herein, the divalent iron as a competing ion for $\mathrm{Sc}^{3+}$, instead of the trivalent one, was studied as it gave more flexibility for $\mathrm{pH}$ adjustment $(<\mathrm{pH} 3.5)$ compare to $\mathrm{Fe}^{3+}(<$ $\mathrm{pH} 2)$. Fig. S4 ( $a, b$ and $c)$ illustrates the behaviour of SF between $\mathrm{Sc}$ and individually $\mathrm{Al}, \mathrm{Ca}, \mathrm{Fe}, \mathrm{Y}$ with equilibrium $\mathrm{pH}$ on three TiPs. Notably, am-TiP gave the highest SF in all cases. At around $\mathrm{pH} 2$, all of the SFs calculated were over 10, with $\mathrm{SF}_{(\mathrm{Sc} / \mathrm{Al})}$ and $\left.\mathrm{SF} / \mathrm{Sc} / \mathrm{Y}\right)$ higher than 1000 and $\mathrm{SF}_{(\mathrm{Sc} / \mathrm{Fe} 2+)}$ around 80 on am-TiP. The results of high SFs indicated that am-TiP might be a promising material for the separation of $\mathrm{Sc}^{3+}$ from all other elements present in the BR leachate. However, layered crystalline materials showed considerably lower SFs in the order of 1 to 10 throughout the tested $\mathrm{pH}$ range.

Ion exchange capacity and stoichiometry. The $\mathrm{Sc}^{3+}$ ion exchange isotherms were determined at around $\mathrm{pH} 2.0$ for all three TiPs (Fig. 7, a). The IECs read from the isotherms are 1.74, 0.55 and 0.22 
meq $\mathrm{g}^{-1}$ for am-, $\alpha$ - and $\mathrm{y}^{-T i P}$, respectively. The ratios of $\mathrm{H}^{+} / \mathrm{Sc}^{3+}$ exchange were determined in isotherm samples, and the related results are expressed in Fig. $\mathbf{7 ( b )}$. The hydronium released was calculated based on $\mathrm{pH}$ differences in the initial and equilibrium system. The results $\mathrm{of} \mathrm{H}^{+} / \mathrm{Sc}^{3+}$ ratios are all in the range of 2 to 4 , except for one point. Large deviations from the theoretical value in the samples with lower initial concentrations are probably due to large uncertainty from small changes in hydronium concentrations. As seen in Fig. 7, the stoichiometry of the ion exchange reaction equals 3 , referring to the expected $\mathrm{Sc}^{3+}$ ion exchange for three $\mathrm{H}^{+}$ions in all three TiP materials.

Comparison of am-TiP with literature results. Table 2 shows the different ion exchange characteristics of various am-TiP reported in literature. ${ }^{23,26,48-50}$ Here we compare only am-TiP because it shows the highest scandium ion exchange capacity and selectivity, and was used for further column study. The presence of $\mathrm{H}_{2} \mathrm{PO}_{4}$ group increases the theoretical IEC because it has two exchangeable hydroniums. The theoretical IEC for the am-TiP ranges from 5.7 to $10.2 \mathrm{meq} \mathrm{g}^{-1}$, and $\mathrm{Na}^{+}$ IEC from 3.7 to $6.3 \mathrm{meq} \mathrm{g}^{-1}$. Our am-TiP shows a high theoretical IEC at 9.79 meq $\mathrm{g}^{-1}$ but moderate $\mathrm{Na}^{+}$ IEC at 5.17 meq $\mathrm{g}^{-1}$. However, it is known that the $\mathrm{Na}^{+}$exchange cannot reach the theoretical value. Higher P:Ti molar ratio is beneficial for the hydrolytic stability of the am-TiP materials ${ }^{45}$ but the higher P:Ti ratio in the synthetic mother liquid does not guarantee the higher ratio in the final composition. The Ti sources (i.e. $\mathrm{TiCl}_{4}$ and $\mathrm{TiOSO}_{4}$ ) are expected to behave differently during the synthesis due to alterations in Ti coordination chemistry. Till today, the formation mechanism of am-TiP is not yet fully understood and the synthesis requires delicate handling to achieve reproducible results.

Mechanistic understanding of selectivity. The ion selectivity on TiP materials is governed by many factors, including but not limited to ionic speciation, hydrated ionic radius, electron configuration, dehydration energy of hydrated ions, temperature and solution ionic strength. To shed light on the 
mechanism of ion selectivity by TiP materials, the solubility product constants $\left(K_{\mathrm{sp}}\right)$ of different metal phosphates were compared. According to the literature, ${ }^{51-53}$ the order of solubility (mol L-1) for four metal phosphates is as follows: $s\left(\mathrm{FePO}_{4}\right)=1.8 \times 10^{-17}<s\left(\mathrm{AlPO}_{4}\right)=10^{-16}<s\left(\mathrm{ScPO}_{4}\right)=3.2 \times 10^{-9}<$ $s\left[\mathrm{Ca}_{3}\left(\mathrm{PO}_{4}\right)_{2}\right]=4.2 \times 10^{-6}$. The order of iron, aluminium and calcium are in line with their selectivity by the material. Contrary to our understanding, scandium, with the second highest solubility of its phosphate, is the most selected ion by TiP materials. Therefore, other factors might provide a dominating effect for scandium selectivity. Table 3 summarizes some important factors regarding the ions available in BR leachate. ${ }^{54-61}$ Ion exchange material can compete with the hydration of ions. In TiPs, Ti atoms are coordinated by phosphate groups in an octahedral manner. The ion exchange behaviour arises from protons of phosphate groups and also via the coordination bond with the phosphoryl group. Our proposed theory is that TiP might favour ions that share a similar radius with the structural forming Ti. According to Shannon, ${ }^{54}$ the lattice radius of octahedrally coordinated $\mathrm{Ti}^{4+}$ is $0.745 \AA$. The 'solvation' of metal ions by $\mathrm{P}=\mathrm{O}$ and $\mathrm{P}-\mathrm{OH}$ groups is energetically more efficient. ${ }^{62}$ Therefore, the exchanged metal ions would preferably be fully-coordinated with the oxygen donated by phosphate groups to achieve minimum surface free energy. It might be logical to compare the ionic radius of 6 -coordinated metal ions with the lattice radius $\mathrm{f}^{\mathrm{Ti}^{4+}}$. Indeed, the 6 -coordinated ionic radius of $\mathrm{Sc}^{3+}$ is a perfect match $(0.745 \AA) .{ }^{54}$ In am-TiP, because the material is made up of nanocrystalline units of TiP octahedrons, this ionic radius-pairing phenomenon is thus assumed to be the predominant cause for the observed selectivity. In comparison, the crystal radius for $\mathrm{Zr}$ (6coordinated) is $0.86 \AA$, and the $\mathrm{Sc}^{3+}$ ion exchange capacity on amorphous zirconium phosphate is much lower than that of am-TiP. ${ }^{63}$ In layered TiPs, the interlayer distances and water molecules within the layer act as molecular sieves to screen the hydrated ions before entering the sorption cavities. 
Our observation from related XRD data indicated that the interlayer distance remained the same after $\mathrm{Sc}^{3+}$ aqua ion exchange, which might limit the capacity and selectivity. Further structural investigations are needed to validate the explanation. Based on the proposed mechanism, it is also possible that other kinds of am-TiP materials have high selectivity towards $\mathrm{Sc}^{3+}$.

Batch elution tests. Batch elution studies were conducted to provide basic information for later column elution such as prerequisites for the choice of acids and concentrations. Due to am-TiP having the highest capacity and selectivity towards $\mathrm{Sc}^{3+}$, only elution on am-TiP was investigated in this study. The first system studied was elution of $\mathrm{Sc}^{3+}$ from Sc-loaded am-TiP. The results in Fig. 8(a) show that the elution $K_{\mathrm{d}}$ values of Sc decreased with increasing acid concentration. Under the same molarity, the elution efficiency followed the sequence of $\mathrm{H}_{2} \mathrm{SO}_{4}>\mathrm{H}_{3} \mathrm{PO}_{4}>\mathrm{HNO}_{3}$. Over $90 \%$ of the elution efficiency could be achieved using $1 \mathrm{M} \mathrm{HNO}_{3}$. The material stability was also assessed here by repeated elution using $1 \mathrm{MHNO}_{3}$, and the corresponding Ti and P hydrolys is fractions for three consecutive cycles were $0.5 \%, 1.5 \%$ and $1.8 \%$ for $\mathrm{Ti}$ and $0.4 \%, 1.2 \%$ and $1.6 \%$ for $\mathrm{P}$. The hydrolysed $\mathrm{Ti}$ would not interfere with the Sc recovery since it could be precipitated easily, and the hydrolysed phosphate only constitutes as minor background salt. Another system studied here was the elution of metal-loaded TiP from an equimolar ternary mixture of $\mathrm{Fe}^{2+}, \mathrm{Ca}$ and $\mathrm{Al}$. Fig. 8(b) illustrates the elution $K_{d}$ values in this system. The $K_{d}$ values of $\mathrm{Fe}^{2+}$ dropped with increasing in acid concentration, and the elution efficiency of acids followed the same order $\left(\mathrm{H}_{2} \mathrm{SO}_{4}>\mathrm{H}_{3} \mathrm{PO}_{4}>\mathrm{HNO}_{3}\right)$ as with scandium. For $\mathrm{Ca}^{2+}$ and $\mathrm{Al}^{3+}$, by contrast, the $K_{\mathrm{d}}$ values almost remained unchanged or changed only slightly. This levelling phenomenon is probably because $\mathrm{Fe}^{2+}$ binds most strongly with am-TiP material, and therefore, increasing acid concentration only affected the elution of $\mathrm{Fe}^{2+}$. Taking advantage of this phenomenon 
could lead to the elution of weakly binding ions at lower acid concentration, followed by firmly binding ions (including $\mathrm{Sc}^{3+}$ ) at higher acid concentration.

Chromatographic separation of $\mathrm{Sc}^{3+}$ from simulated BR leachate. The simulated BR leachate at $\mathrm{pH}$ 1.5 was prepared according to the composition reported by Roosen. ${ }^{21}$ This specific composition originated from a Greek BR. Tetravalent ions were first removed from the leachate by means of alkaline precipitation. By adjusting the $\mathrm{pH}$ from 1.5 to 2.0 with $\mathrm{NaOH}$, almost all $\mathrm{Si}^{4+}$ and $\mathrm{Ti}^{4+}$ were removed (Table 3), with only $2.5 \%$ of $\mathrm{Sc}^{3+}$ loss. Therefore, $\mathrm{Si}^{4+}$ and $\mathrm{Ti}^{4+}$ were not considered in further separation. The resulting solution was loaded onto an am-TiP column to study the breakthrough behaviour. As illustrated in Fig. $9(a), \mathrm{Na}^{+}, \mathrm{Al}^{3+}, \mathrm{Ca}^{2+}$ and $\mathrm{La}^{3+}$ brokethrough the column before $5 \mathrm{BV}$. $\mathrm{Fe}^{3+}$ started to breakthrough at $18 \mathrm{BV}$ and $\mathrm{Sc}^{3+}$ at $22 \mathrm{BV}$. This further confirmed the similarity between trivalent iron and scandium. In a further test, to achieve better separation, ca. $8 \mathrm{BV}$ of the simulant was loaded onto the am-TiP column, and on-column reduction of $\mathrm{Fe}^{3+}$ was performed by conditioning the column with $2 \mathrm{BV}$ of $0.05 \mathrm{M}$ sodium sulphite. The reducing agent employed here can be recycled to lower its consumption. The elution chromatogram for this run is presented in Fig. $\mathbf{9}(b)$ by means of cumulative elution percentage versus bed volume. With $0.2 \mathrm{M}$ nitric acid, the majority of Fe (including $\mathrm{Fe}^{2+}$ and $\mathrm{Fe}^{3+}$ ) and $\mathrm{Al}^{3+}$ as well as all of the $\mathrm{Na}^{+}, \mathrm{La}^{3+}$ and $\mathrm{Ca}^{2+}$ eluted from the column. After this, $0.3 \mathrm{M}$ nitric acid further eluted some $\mathrm{Fe}$ and $\mathrm{Al}^{3+}$, however, $\mathrm{Sc}^{3+}$ also started to come out of the column. By elution with a mixed acid comprising $0.5 \mathrm{M}$ nitric and $0.5 \mathrm{M}$ phosphoric acid, all $(98.9 \%) \mathrm{Sc}^{3+}$ contents eluted. Combining the final $30 \mathrm{BV}$ of eluent, we obtained a solution containing only $\mathrm{Sc}^{3+}, \mathrm{Fe}$ and $\mathrm{Al}^{3+}$ at concentrations of $0.35,1.43$ and $0.28 \mathrm{ppm}$, respectively, while in the original feed solution, the corresponding $\mathrm{Sc}^{3+}, \mathrm{Fe}^{3+}$ and $\mathrm{Al}^{3+}$ concentrations were 1.96, 72.3 and $636 \mathrm{ppm}$. The concentration ratio of Sc/Fe increased from $1 / 35$ to $1 / 4$ and Sc/Al from $1 / 318$ to $1 / 1.2$ through a single cycle of 
chromatographic separation. The on-column reduction conditions and other elution agents are now being further studied to achieve full reduction and better separation.

Reusability of am-TiP. The am-TiP underwent five cycles of sorption and elution to investigate its reusability. The equilibrium $\mathrm{pH}$ of the five sorption cycles were measure to be $2.1 \pm 0.1$. As illustrated in Fig. S5, slight decrease of Sc uptake was observed. However, the SFsc/Al stayed on a relatively constant level under the logarithmic scale. The results indicate good reusability of the material.

\section{CONCLUSION}

TiP materials exhibit excellent host structures for the separation of trace scandium from complex BR acid leachate. Amorphous TiP has the highest scandium selectivity among the three TiPs tested. The unique selectivity towards $\mathrm{Sc}^{3+}$ is assumed to originate from the matching between the lattice radius of $\mathrm{Ti}^{4+}$ and the ionic radius of $\mathrm{Sc}^{3+}$. The optimum separation $\mathrm{pH}$ was chosen at 2.0 for both capacity and selectivity considerations. The biggest challenges in the separation of $\mathrm{Sc}^{3+}$ from BR leachate are the interference from $\mathrm{Fe}^{3+}$ and $\mathrm{Al}^{3+}$. By employing on-column reduction, $\mathrm{Fe}^{3+}$ was partially converted to less-favoured $\mathrm{Fe}^{2+}$ and the amount of reductant needed was minimized. All sodium, calcium and lanthanides and the majority of iron and aluminium were eluted from the column by $0.2 \mathrm{M}$ nitric acid. Almost all scandium was then eluted by a mixed acid comprising nitric and phosphoric acid, with $\mathrm{Sc} / \mathrm{Fe}$ and Sc/Al enrichment factors at 9 and 265, respectively. A pure scandium fraction is expected to be obtained by tandem chromatographic separations utilizing am-TiP. Overall, the TiP materials showed promising applicability for trace scandium recovery from complex waste streams. 


\section{ACKNOWLEDGEMENTS}

The research leading to these results has received funding from the European Community's Horizon 2020 Programme under Grant Agreement no. 636876 (MSCA-ETN REDMUD). This paper reflects only the author's view, exempting the Community from any liability. Project website:

http://etn.redmud.org/. The authors thank Dr. Juhani Virkanen for his helpful pieces of advice in MPAES analysis. Pasi Heikkilä is acknowledged for his support in XRD measurements.

\section{ASSOCIATED CONTENT}

Supporting Information. The Supporting Information is available free of charge on the ACS

Publications website: ATR-FTIR spectra (Fig. S1) and UV/Vis diffuse reflectance spectra (Fig. S2) of the synthesized TiP materials, XRD pattern of the am-TiP after treatment at $1000^{\circ} \mathrm{C}$ (Fig. S3), effects of solution equilibrium $\mathrm{pH}$ on separation factors of TiP materials from binary equimolar mixtures (Fig. S4), scandium uptake and SFsc/Al of am-TiP in repeated sorption-elution cycles (Fig. S5), conceptual scandium separation sheet from bauxite residue utilizing TiP ion exchange columns (Scheme S1) and line deconvolution results of the NMR spectrum of $\gamma$-TiP (Table S1). 


\section{REFERENCES}

1. Massari, S.; Ruberti, M. Rare earth elements as critical raw materials: Focus on international markets and future strategies. Resour. Policy, 2013, 38, 36-43.

(doi: 10.1016/j.resourpol.2012.07.001)

2. Baba, Y.; Fukami,A.; Kubota, F.; Kamiya, N.; Goto, M. Selective extraction of scandium from yttrium and lanthanides with amic acid-type extractant containing alkylamide and glycine moieties. RSCAdv., 2014, 4, 50726-50730.

(doi: 10.1039/C4RA08897B)

3. Wang, W.; Pranolo, Y.; Cheng, C. Y. Metallurgical processes for scandium recovery from various resources: A review. Hydrometallurgy, 2011, 108, 100-108.

(doi: 10.1016/j.hydromet.2011.03.001)

4. Jindal, V.; De, P. K.; Venkateswarlu, Effect of $\mathrm{Al}_{3}$ Sc precipitates on the work hardening behavior of aluminum-scandium alloys. K. Mater. Lett., 2006, 60, 3373-3375.

(doi: 10.1016/j.matlet.2006.03.017)

5. Weber, A.; Ivers-Tiffée, E. Materials and concepts for solid oxide fuel cells (SOFCs) in stationary and mobile applications. J. Power Sources, 2004, 127, 273-283.

(doi: 10.1016/j.jpowsour.2003.09.024)

6. Van Nguyen, N.; lizuka, A.; Shibata, E.; Nakamura,T. Study of adsorption behavior of a new synthesized resin containing glycol amic acid group for separation of scandium from aqueous solutions.

Hydrometallurgy, 2016, 165, 51-56.

(doi: 10.1016/j.hydromet.2015.11.016)

7. Guyonnet, D.; Planchon, M.; Rollat, A.; Escalon, V.; Tuduri, J.; Charles, N.; Vaxelaire, S.; Dubois D.; Fargier, H. Material flow analysis applied to rare earth elements in Europe. J. Clean. Prod., 2015, 107, 215-228.

(doi: 10.1016/j.jclepro.2015.04.123)

8. Liu, Y.; Naidu, R. Hidden values in bauxite residue (red mud): Recovery of metals. Waste Manage., 2014, 34, 2662-2673.

(doi: 10.1016/j.wasman.2014.09.003)

9. Gräfe, M.; Power, G.; Klauber, C. Bauxite residue issues: III. Alkalinityand associated chemistry. Hydrometallurgy, 2011, 108, 60-79.

(doi: 10.1016/j.hydromet.2011.02.004)

10. Power, G.; Gräfe, M.; Klauber, C. Bauxite residue issues: I. Current management, disposal and storage practices. Hydrometallurgy, 2011, 108, 33-45.

(doi: 10.1016/j.hydromet.2011.02.006)

11. Qin, S.; Wu, B. Reducing the radiation dose of red mud to environmentally acceptable levels as an example of novel ceramic materials. Green Chem. 2011, 13, 2423-2427.

(doi: 10.1039/C1GC15452D)

12. Samouhos, M.; Taxiarchou, M.; Tsakiridis, P. E.; Potiriadis, K. Greek "red mud" residue: A study of microwave reductive roasting followed by magnetic sepa ration for a metalliciron recovery process. $J$. Hazard. Mater., 2013, 254-255, 193-205.

(doi: 10.1016/j.jhazmat.2013.03.059)

13. Liu, W.; Yang, J.; Xiao, B. Application of Bayer red mud for iron recovery and building material production from alumosilicate residues. J. Hazard. Mater., 2009, 161, 474-478.

(doi: 10.1016/j.jhazmat.2008.03.122)

14. Zhang, R.; Zheng, S.; Ma, S.; Zhang, Y. Recovery of alumina and alkali in Bayer red mud by the formation of andradite-grossular hydrogarnet in hydrothermal process. J. Hazard. Mater., 2011, 189, 827-835. 
(doi: 10.1016/j.jhazmat.2011.03.004)

15. Pontikes, Y.; Angelopoulos, G. N. Bauxite residue in cement and cementitious applications: Current status and a possible way forward. Resour. Conserv. Recy., 2013, 73, 53-63.

(doi: 10.1016/j.resconrec.2013.01.005)

16. Shaoquan, X.; Suqing, L. Review of the extractive metallurgy of scandium in China (1978-1991).

Hydrometallurgy, 1996, 42, 337-343.

(doi: 10.1016/0304-386X(95)00086-V)

17. Borra, C. R.; Pontikes, Y.; Binnemans, K; Van Gerven, T. Leaching of rare earths from bauxite residue (red mud). Miner. Eng., 2015, 76, 20-27.

(doi: 10.1016/j.mineng.2015.01.005)

18. Ochsenkühn-Petropoulou, M. T.; Hatzilyberis, K. S.; Mendrinos, L. N.; Salmas, C. E. Pilot-Plant Investigation of the Leaching Process for the Recovery of Scandium from Red Mud. Ind. Eng. Chem.

Res., 2002, 41, 5794-5801.

(doi: 10.1021/ie011047b)

19. Wang, W.; Cheng, C. Y. Separation and purification of scandium by solvent extraction and related technologies: a review. J. Chem. Technol. Biotechnol., 2011, 86, 1237-1246.

(doi: 10.1002/jctb.2655)

20. Onghena, B.; Binnemans, K. Recovery of Scandium(III) from Aqueous Solutions by Solvent Extraction with the Functionalized Ionic Liquid Betainium Bis(trifluoromethylsulfonyl)imide. Ind. Eng. Chem. Res., 2015, 54, 1887-1898.

(doi: 10.1021/ie504765v)

21. Roosen, J.; Van Roosendael, S.; Borra, C. R.; Van Gerven, T.; Mullens, S.; Binnemans, K. Recovery of scandium from leachates of Greek bauxite residue by adsorption on functionalized chitosan-silica hybrid materials. Green Chem., 2016, 18, 2005-2013.

(doi: 10.1039/C5GC02225H)

22. Zhou, H.; Li, D.; Tian, Y.; Chen, Y. Extraction of scandium from red mud by modified activated carbon and kinetics study. Rare Metals, 2008, 27, 223-227.

(doi: 10.1016/S1001-0521(08)60119-9)

23. Bortun, A. I.; Bortun, L. N.; Clearfield, A.; Khainakov, S. A.; Strelko, V. V.; Khryaschevskii, V. N.; Kvashenko, A. P.; Voitko, I. I. Synthesis and characterization of ion exchange properties of s pherically granulated titanium phosphate. Solvent Extr. Ion Exc., 1997, 15, 515-532.

(doi: 10.1080/07366299708934491)

24. Alberti, G.; Casciola, M.; Costantino, U.;Vivani, R. Layered and pillared metal(IV) phosphates and phosphonates. Adv. Mater., 1996, 8, 291-303.

(doi: 10.1002/adma.19960080405)

25. Serre, C.; Taulelle, F.; Ferey, G. Rational design of porous titanophosphates. Chem. Comm., 2003, 27552765.

(doi: 10.1039/B304703B)

26. Trublet, M.; Maslova, M. V.; Rusanova, D.; Antzutkin, O. N. Mild syntheses and surface characterization of amorphous $\mathrm{TiO}(\mathrm{OH})\left(\mathrm{H}_{2} \mathrm{PO}_{4}\right) \cdot \mathrm{H}_{2} \mathrm{O}$ ion-exchanger. Mater. Chem, Phys., 2016, 183, 467-475.

(doi: 10.1016/j.matchemphys.2016.09.002)

27. Suarez, M.; Garcia, J. R.; Rodriguez, J. Thermodynamic treatment of proton/sodium(1+) ion exchange on .alpha.-titanium phosphate. J. Phys. Chem., 1984, 88, 159-162.

(doi: 10.1021/j150645a036)

28. Sahu, B. B.; Parida, K. Cation Exchange and Sorption Properties of Crystalline $\alpha$-Titanium(IV) Phosphate. J. Colloid Interf. Sci. , 2002, 248, 221-230.

(doi: 10.1006/jcis.2001.7818) 
29. Clearfield, A.; Roberts, B. D. Pillaring of layered zirconium and titanium phosphates. Inorg. Chem., 1988, 27, 3237-3240.

(doi: 10.1021/ic00291a040)

30. Alberti, G.; Giammari, G.; Grassini-Strazza, G. Chromatographic behaviour of inorganic ions on crystalline titanium phosphate or zirconium phosphate thin layers. J. Chromatogr. A, 1967, 28, 118-123. (doi: 10.1016/S0021-9673(01)85936-7)

31. Clearfield, A. Recent advances in metal phosphonate chemistry. Curr. Opin. Solid St. M., 1996, 1, 268278.

(doi: 10.1016/S1359-0286(96)80094-5)

32. Zhu, Y.-P.; Ren, T.-Z.; Yuan, Z.-Y.Insights into mesoporous metal phosphonate hybrid materials for catalysis. Catal. Sci. Technol., 2015, 5, 4258-4279.

(doi: 10.1039/C5CY00107B)

33. Zhu, Y.; Yoneda, K.; Kanamori, K.; Takeda, K.; Kiyomura, T.; Kurata, H.; Nakanishi, K. Hierarchically porous titanium phosphate monoliths and their crystallization behavior in ethyleneglycol. NewJ. Chem., 2016, 40, 4153-4159.

(doi: 10.1039/C5NJ02820E)

34. Baig, U.; Rao, R. A. K.; Khan, A. A.; Sanagi, M. M.; Gondal, M. A. Removal of carcinogenic hexavalent chromium from aqueous solutions using newly synthesized and characterized polypyrroletitanium(IV)phosphate nanocomposite. Chem. Eng. J., 2015, 280, 494-504.

(doi: 10.1016/j.cej.2015.06.031)

35. Alberti, G.; Cardini-Galli, P.; Costantino, U.; Torracca, E. Crystalline insoluble salts of polybasic metals-I Ion-exchange properties of crystalline titanium phosphate. J. Inorg. Nucl. Chem., 1967, 29, 571-578. (doi: 10.1016/0022-1902(67)80063-0)

36. Bao, C.; Guo, Y.; Song, L.; Lu, H.; Yuan, B.; Hu, Y. Facile Synthesis of Poly(vinyl alcohol)/ $\alpha$-Titanium Phosphate Nanocomposite with Markedly Enhanced Properties. Ind. Eng. Chem. Res., 2011, 50, 1110911116.

(doi: 10.1021/ie200700t)

37. Andersen, A. M. K.; Norby, P. Inorg. Chem., Structural Aspects of the Dehydration and Dehydroxylation of $\gamma$-Titanium Phosphate, $\gamma$-Ti $\left(\mathrm{PO}_{4}\right)\left(\mathrm{H}_{2} \mathrm{PO}_{4}\right) \cdot 2 \mathrm{H}_{2} \mathrm{O}$. Inorg. Chem., 1998, 37, 4313-4320. (doi: 10.1021/ic9801894)

38. Wang, X.; Yang, X.; Cai, J.; Miao, T.; Li, L.; Li, G.; Deng, D.; Jiang, L.; Wang, C. Novel flower-like titanium phosphate microstructures and their application in lead ion removal from drinking water. J. Mater. Chem. A, 2014, 2, 6718-6722.

(doi: 10.1039/C4TA00246F)

39. Pan, B.; Zhang, Q.; Du, W.; Zhang, W.; Pan, B.; Zhang, Q.; Xu, Z.; Zhang, Q. Selective heavy metal removal from waters by amorphous zirconium phosphate: Behavior and mechanism. Water Res., 2007, 41, 3103-3111.

(doi: 10.1016/j.watres.2007.03.004)

40. García-Granda, S.; Khainakov, S. A.; Espina, A.; García, J. R.; Castro, G. R.; Rocha, J.; Mafra, L. Revisiting the Thermal Decomposition of Layered $\gamma$-Titanium Phosphate and Structural Elucidation of Its Intermediate Phases. Inorg. Chem., 2010, 49, 2630-2638.

(doi: 10.1021/ic901254j)

41. Stanghellini, P. L.; Boccaleri, E.; Diana, E.; Alberti, G.; Vivani, R. Vibrational Study of Some Layered Structures Based on Titanium and Zirconium Phosphates, Inorg. Chem., 2004, 43, 5698-5703. (doi:10.1021/ic049565c)

42. Bortun, A.; Jaimez, E.; Llavona, R.; Garcia, J. R.; Rodriguez, J. Formation of crystalline titanium(IV) phosphates from titainum(III) solutions. Mater. Res. Bull., 1995, 30, 413-420.

(doi: 10.1016/0025-5408(95)00019-4) 
43. Garcia-Granda, S.; Khainakov, S. A.; Espina, A.; Garcia, J. R. Revisiting the thermal decomposition of layered $\gamma$-titanium phosphate and structural elucidation of its intermediate phases. Inorg. Chem., 2010, 49, 2630-2638.

(doi:10.1021/ic901254j)

44. Allulli, S.; Ferragina, C.; La Ginestra, A.; Massucci, M. A.; Tomassini, N. Preparation and ion-exchange properties of a new phase of crystalline titanium phosphate, $\mathrm{Ti}\left(\mathrm{HPO}_{4}\right)_{2} \cdot 2 \mathrm{H}_{2} \mathrm{O}$. J. Inorg. Nucl. Chem., 1977, 39, 1043-1048.

(doi: 10.1016/0022-1902(77)80261-3)

45. Trublet, M.; Maslova, M. V.; Rusanova, D.; Antzutkin, O. N. Sorption performances of $\mathrm{TiO}(\mathrm{OH})\left(\mathrm{H}_{2} \mathrm{PO}_{4}\right) \cdot \mathrm{H}_{2} \mathrm{O}$ in synthetic and mine waters. RSCAdv. , 2017, 7, 1989-2001.

(doi: 10.1039/C6RA25410A)

46. Helfferich, F. G. Ion exchange, Courier Corporation, 1962.

47. Baes, C. F.; Mesmer, R. E. Hydrolysis of cations, Wiley, 1976.

48. Suarez, M.; Garcia, J. R.; Rodriguez, J. The preparation, characterisation and ion exchange properties of an amorphous titanium phosphate. Mater. Chem. Phys., 1983, 8, 451-458.

(doi:10.1016/0254-0584(83)90065-2)

49. Maslova, M. V.; Rusanova, D.; Naydenov, V.; Antzutkin, O. N.; Gerasimova, L. G., Synthesis, characterization, and sorption properties of amorphous titanium phosphate and silica-modified titanium phosphates. Inorg. Chem., 2008, 47, 11351-11360.

(doi: 10.1021/ic801274z)

50. Maslova, M.V.; Chugunov, A.S.; Gerasimova, L.G.; Konovalova, N. V., Acid-base and sorption properties of amorphous titanium phosphate. Radiochemistry, 2013, 55, 323-328.

(doi:10.1134/S1066362213040097)

51. Ferna, E.; Gil, F.; Ginebra, M.; Driessens, F.; Planell, J.; Best, S. Calcium phosphate bone cements for clinical applications. Part I: Solution chemistry. J. Mater. Sci-Mater. M., 1999, 10, 169-176. (doi: 10.1023/A:1008937507714)

52. Wood, S. A.; Samson, I. M. The aqueous geochemistry of gallium, germanium, indium and scandium. Ore Geol. Rev., 2006, 28, 57-102.

(doi: 10.1016/j.oregeorev.2003.06.002)

53. Chang, S.; Jackson, M. Solubility Product of Iron Phosphate. Soil Sci. Soc. Am. J., 1957, 21, 265-269. (doi: 10.2136/sssaj1957.03615995002100030005x)

54. Shannon, R. Revised effective ionic radii and systematic studies of interatomic distances in halides and chalcogenides. Acta Crystallogr. A, 1976, 32, 751-767.

(doi: 10.1107/S0567739476001551)

55. Spångberg, D.; Hermansson, K.; Lindqvist-Reis, P.; Jalilehvand, F.; Sandström, M.; Persson, I. Model Extended X-ray Absorption Fine Structure (EXAFS) Spectra from Molecular Dynamics Data for $\mathrm{Ca}^{2+}$ and $\mathrm{Al}^{3+}$ Aqueous Solutions. J. Phys. Chem. B, 2000, 104, 10467-10472.

(doi: 10.1021/jp000247i)

56. Jalilehvand, F.; Spångberg, D.; Lindqvist-Reis, P.; Hermansson, K.; Persson, I.; Sandström, M. Hydration of the Calcium Ion. An EXAFS, Large-Angle X-ray Scattering, and Molecular Dynamics Simulation Study. J. Am. Chem. Soc., 2001, 123, 431-441.

(doi: 10.1021/ja001533a)

57. Lundberg, D.; Ullström, A.-S.; D'Angelo, P.; Persson, I. A structural study of the hydrated and the dimethylsulfoxide, $\mathrm{N}, \mathrm{N}^{\prime}$-dimethylpropyleneurea, and N,N-dimethylthioformamide solvated iron(II) and iron(III) ions in solution and solid state. Inorg. Chim. Acta, 2007, 360, 1809-1818.

(doi: 10.1016/j.ica.2006.09.014) 
58. Persson, I.; D'Angelo, P.; De Panfilis, S.; Sandström, M.; Eriksson, L. Hydration of Lanthanoid(III) lons in Aqueous Solution and Crystalline Hydrates Studied by EXAFS Spectroscopy and Crystallography: The Myth of the "Gadolinium Break". Chem.-Eur. J., 2008, 14, 3056-3066.

(doi: 10.1002/chem.200701281)

59. Mähler, J.; Persson, I. A Study of the Hydration of the Alkali Metal Ions in Aqueous Solution. Inorg. Chem., 2012, 51, 425-438.

(doi: 10.1021/ic2018693)

60. Lindqvist-Reis, P.; Persson, I.; Sandstrom, M. The hydration of the scandium(III) ion in aqueous solution and crystalline hydrates studied by XAFS spectroscopy, large -angleX-ray scattering and crystallography. Dalton Transactions, 2006, 3868-3878.

(doi: 10.1039/B604267H)

61. Lindqvist-Reis, P.; Lamble, K.; Pattanaik, S.; Persson, I.; Sandström, M. Hydration of the Yttrium(III) Ion in Aqueous Solution. An X-ray Diffraction and XAFS Structural Study. J. Phys. Chem. B, 2000, 104, 402408.

(doi: 10.1021/jp992101t)

62. Strelko, V.; Karaseva, T. Adsorbtsiya iAdsorbenty, 1977, 5, 71-77.

63. Korovin, V.; Shestak, Y.; Pogorelov, Y. in Scandium: compounds, productions, and applications, ed. V. A. Greene, Nova Science Publishers, Inc, 2010, ch. 3, pp. 77-100. (ISBN: 978-161761465-1) 


\section{TABLES AND FIGURES}

Table 1. Summary of chemical formulae and ion exchange capacities for TiPs.

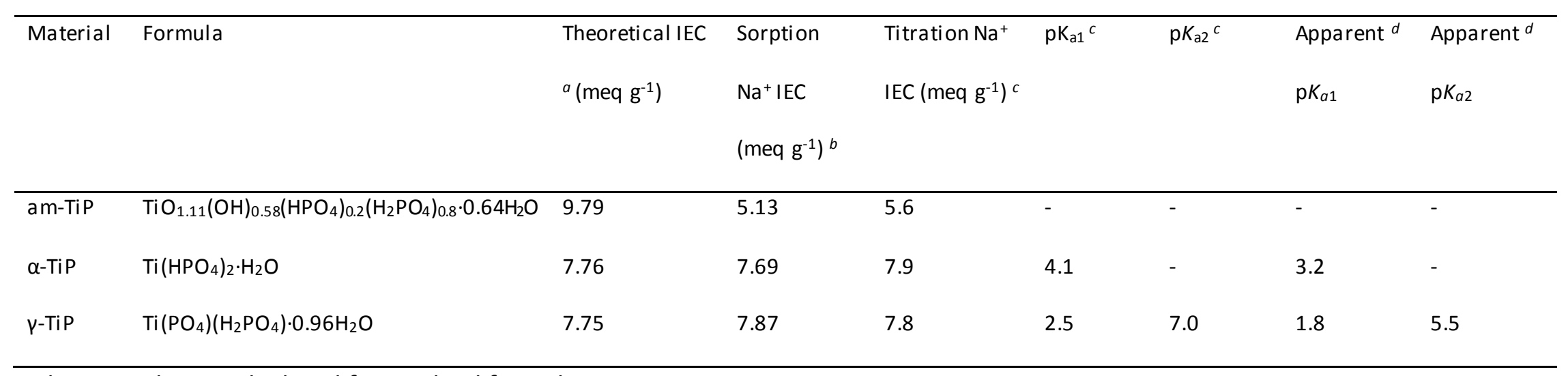

a Theoretical IECs calculated from solved formulae.

${ }^{b}$ Calculated from batch $\mathrm{Na}_{2} \mathrm{CO}_{3}$ sorption uptake.

${ }^{c}$ Derived from titration without added salts.

${ }^{d}$ Derived from titration with $0.1 \mathrm{M} \mathrm{NaNO}_{3}$ background. 
Table 2. Ion exchange characteristics of various am-TiP materials reported in literature.

\begin{tabular}{|c|c|c|c|c|c|}
\hline Formula & Ti source & $\begin{array}{l}\text { P: Ti molar ratio } \\
\text { in mother liquid }\end{array}$ & $\begin{array}{l}\text { Theoretical IEC } \\
\left(\text { meq } \mathrm{g}^{-1}\right)\end{array}$ & $\begin{array}{l}\text { Experimental IEC } \\
\text { by } \mathrm{Na}^{+}\left(\text {meq g }{ }^{-1}\right)\end{array}$ & Reference \\
\hline $\mathrm{Ti}_{4} \mathrm{O}_{2}(\mathrm{OH})_{4}\left(\mathrm{HPO}_{4}\right)_{3}\left(\mathrm{H}_{2} \mathrm{PO}_{4}\right)_{2} \cdot 3 \mathrm{H}_{2} \mathrm{O}$ & $\mathrm{TiCl}_{4}$ & $3: 1$ & $8.46^{*}$ & 3.66 & [48] \\
\hline $\mathrm{TiO}_{1.25}(\mathrm{OH})_{0.47}\left(\mathrm{HPO}_{4}\right)_{0.13}\left(\mathrm{H}_{2} \mathrm{PO}_{4}\right)_{0.77} \cdot 2.3 \mathrm{H}_{2} \mathrm{O}$ & $\mathrm{TiCl}_{4}$ & $2: 1$ & 8.2 & $4.7\left(\mathrm{~K}^{+}\right)$ & {$[23]$} \\
\hline $\mathrm{Ti}(\mathrm{OH})_{1.36}\left(\mathrm{HPO}_{4}\right)_{1.32} \cdot 2.3 \mathrm{H}_{2} \mathrm{O}$ & $\mathrm{TiOSO}_{4}$ & $2: 1$ & 5.7 & N.A. & [49] \\
\hline $\mathrm{Ti}(\mathrm{OH})_{1.2}\left(\mathrm{HPO}_{4}\right)_{1.28}\left(\mathrm{H}_{2} \mathrm{PO}_{4}\right)_{0.24} \cdot 2.5 \mathrm{H}_{2} \mathrm{O}$ & $\mathrm{TiOSO}_{4}$ & $2: 1$ & 6.78 & 5.56 & {$[50]$} \\
\hline $\mathrm{TiO}(\mathrm{OH})\left(\mathrm{H}_{2} \mathrm{PO}_{4}\right) \cdot \mathrm{H}_{2} \mathrm{O}$ & $\mathrm{TiOSO}_{4}$ & $2: 1$ & $10.2^{*}$ & 6.30 & {$[26]$} \\
\hline $\mathrm{TiO}_{1.11}(\mathrm{OH})_{0.58}\left(\mathrm{HPO}_{4}\right)_{0.2}\left(\mathrm{H}_{2} \mathrm{PO}_{4}\right)_{0.8} \cdot 0.64 \mathrm{H}_{2} \mathrm{O}$ & $\mathrm{TiCl}_{4}$ & $3.85: 1$ & 9.79 & 5.13 & This work \\
\hline
\end{tabular}

* our calculation based on the given formulae. 
Table 3. Electron configuration, classical ionic radius, coordination number and metal-oxygen bond length of the ions present in BR leachate.

\begin{tabular}{|c|c|c|c|c|}
\hline Ion & $\begin{array}{l}\text { Electron } \\
\text { configuration }\end{array}$ & $\begin{array}{l}\text { Shannon ionic radius } \\
\text { (Å) } 54\end{array}$ & $\begin{array}{l}\text { Coordination } \\
\text { number }\end{array}$ & M-O bond length $(\AA)$ \\
\hline $\mathrm{Al}^{3+}$ & {$[\mathrm{Ne}]$} & 0.535 & $6^{*}$ & $1.96^{55}$ \\
\hline \multirow[t]{2}{*}{$\mathrm{Ca}^{2+}$} & {$[\mathrm{Ar}]$} & 1.12 & $8^{*}$ & $2.46^{56}$ \\
\hline & & 1.00 & 6 & - \\
\hline $\mathrm{Fe}^{2+}$ & {$[\mathrm{Ar}] 3 \mathrm{~d}^{6}$} & 0.78 & $6^{*}$ & $2.118^{57}$ \\
\hline $\mathrm{Fe}^{3+}$ & {$[\mathrm{Ar}] 3 \mathrm{~d}^{5}$} & 0.645 & $6^{*}$ & $1.994^{57}$ \\
\hline \multirow[t]{4}{*}{$\operatorname{Ln}^{3+}$} & {$[X e] 4 f^{0}-4 f^{14}$} & $\mathrm{La}^{3+} 1.216(\max )$ & $9 *$ & $\mathrm{La}^{3+} 2.55(\max )^{58}$ \\
\hline & & $\mathrm{Lu}^{3+} 1.032(\mathrm{~min})$ & & $\mathrm{Lu}^{3+} 2.36(\mathrm{~min})$ \\
\hline & & $\mathrm{La}^{3+} 1.032(\max )$ & 6 & - \\
\hline & & $\mathrm{Lu}^{3+} 0.861(\mathrm{~min})$ & & \\
\hline $\mathrm{Na}^{+}$ & {$[\mathrm{Ne}]$} & 1.02 & $6^{*}$ & $2.42^{59}$ \\
\hline \multirow[t]{2}{*}{$\mathrm{Sc}^{3+}$} & {$[\mathrm{Ar}]$} & 0.870 & 8 & $2.17^{60}$ \\
\hline & & 0.745 & $6^{*}$ & - \\
\hline \multirow[t]{2}{*}{$\mathrm{Y}^{3+}$} & {$[\mathrm{Kr}]$} & 1.019 & $8^{*}$ & $2.37^{61}$ \\
\hline & & 0.90 & 6 & - \\
\hline $\mathrm{Ti}^{4+}$ & {$[\mathrm{Ar}]$} & 0.605 & 6 & - \\
\hline
\end{tabular}

Note: The number of water molecules coordinated in the metal aqua ions are marked with asterisks. 
Table 3. Elemental composition (ppm) of simulated BR leaching solution at $\mathrm{pH} 1.5$ and after $\mathrm{pH}$ adjustment to 2.0 and filtration.

\begin{tabular}{lllllllll}
\hline Element & Na & Ca & Al & Fe & Si & Ti & Sc & La \\
\hline BR leachate pH 1.5 & 1216 & 1069 & 641 & 94.3 & 572 & 95.7 & 2.01 & 5.30 \\
BR leachate pH 2.0 & 2232 & 1037 & 636 & 72.3 & 0.1 & 3.1 & 1.96 & 5.24 \\
\hline
\end{tabular}




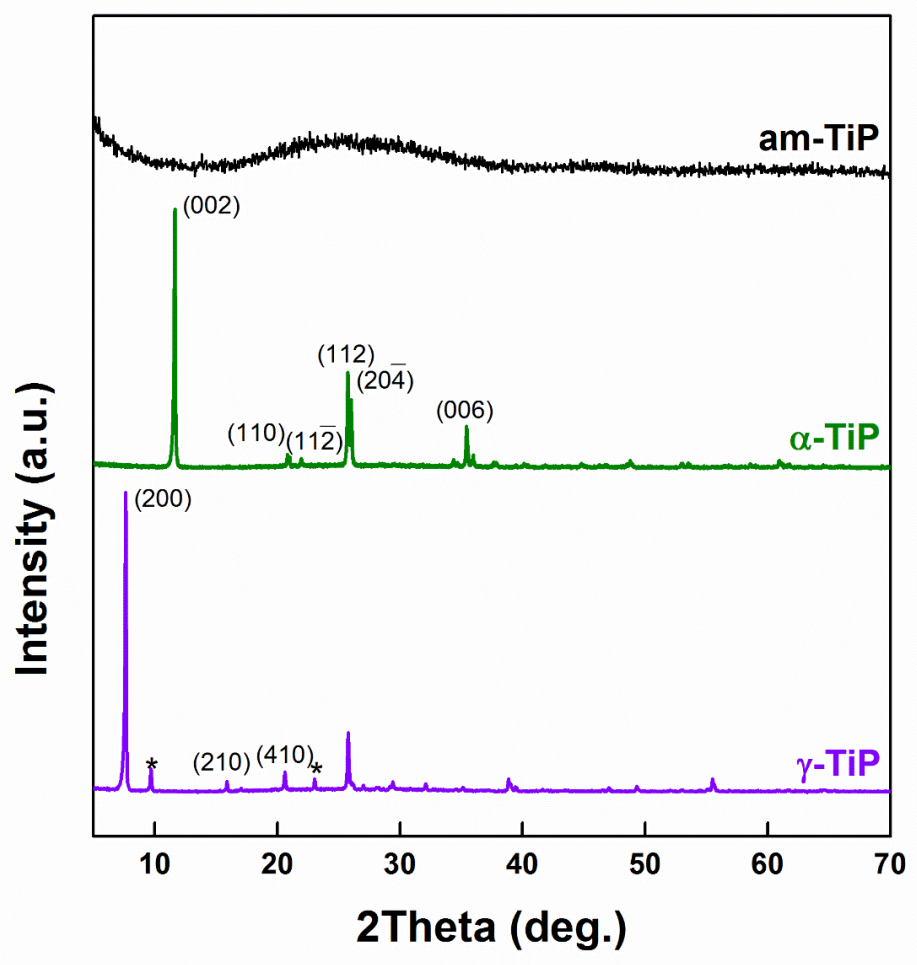

Figure 1. Powder XRD patterns of the as-synthesized am-TiP, $\alpha$-TiP and $y$-TiP. Miller indices of the planes corresponding to the major diffraction peaks are provided in parentheses. 


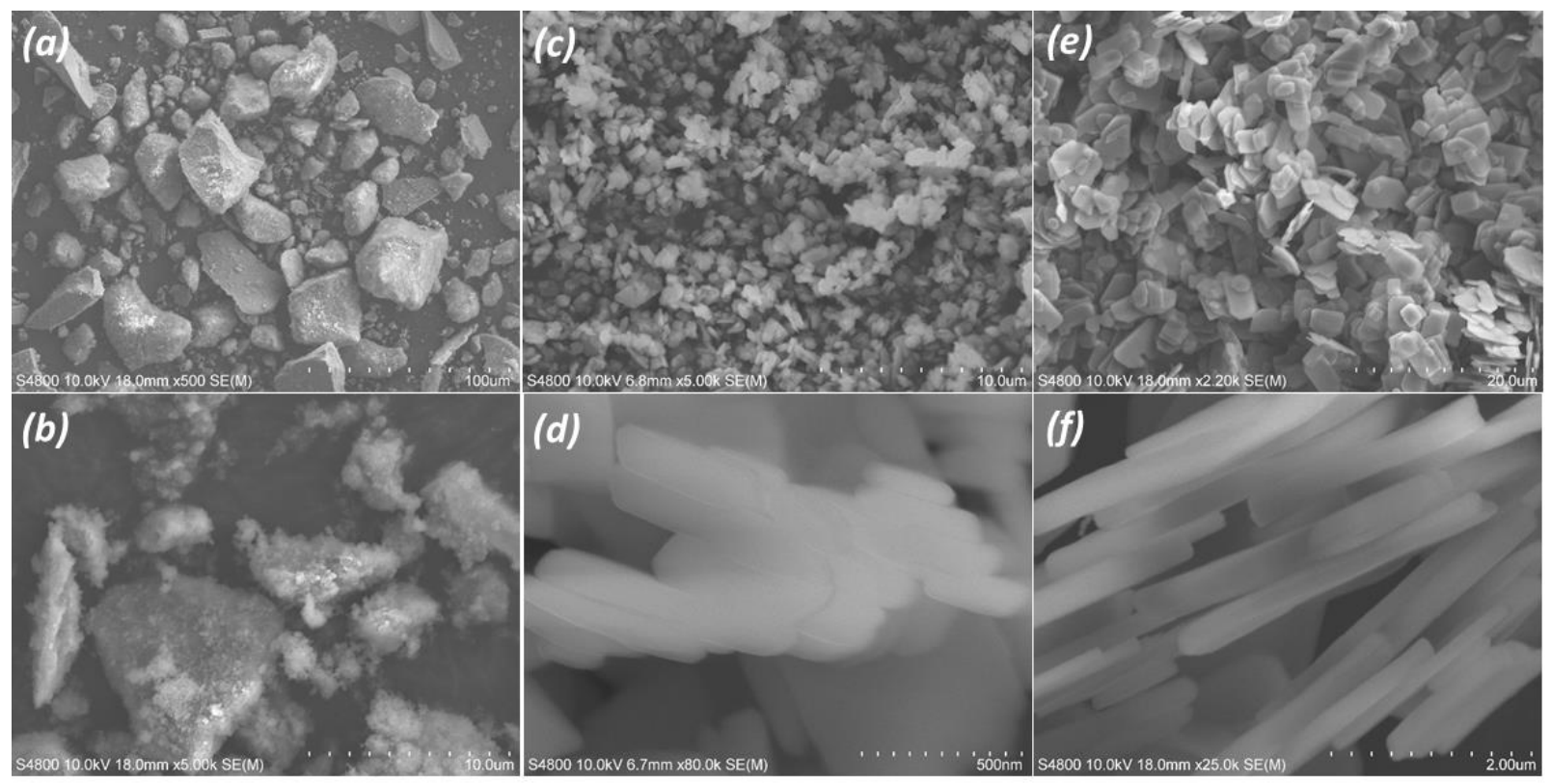

Figure 2. FE-SEM micrographs of am-TiP $(a$ and $b), \alpha-\operatorname{TiP}(c$ and $d)$ and $\gamma$-TiP $(e$ and $f) . a, c$ and $e$ are captured with lower magnification and $b, d$ and $f$ with higher magnification. 


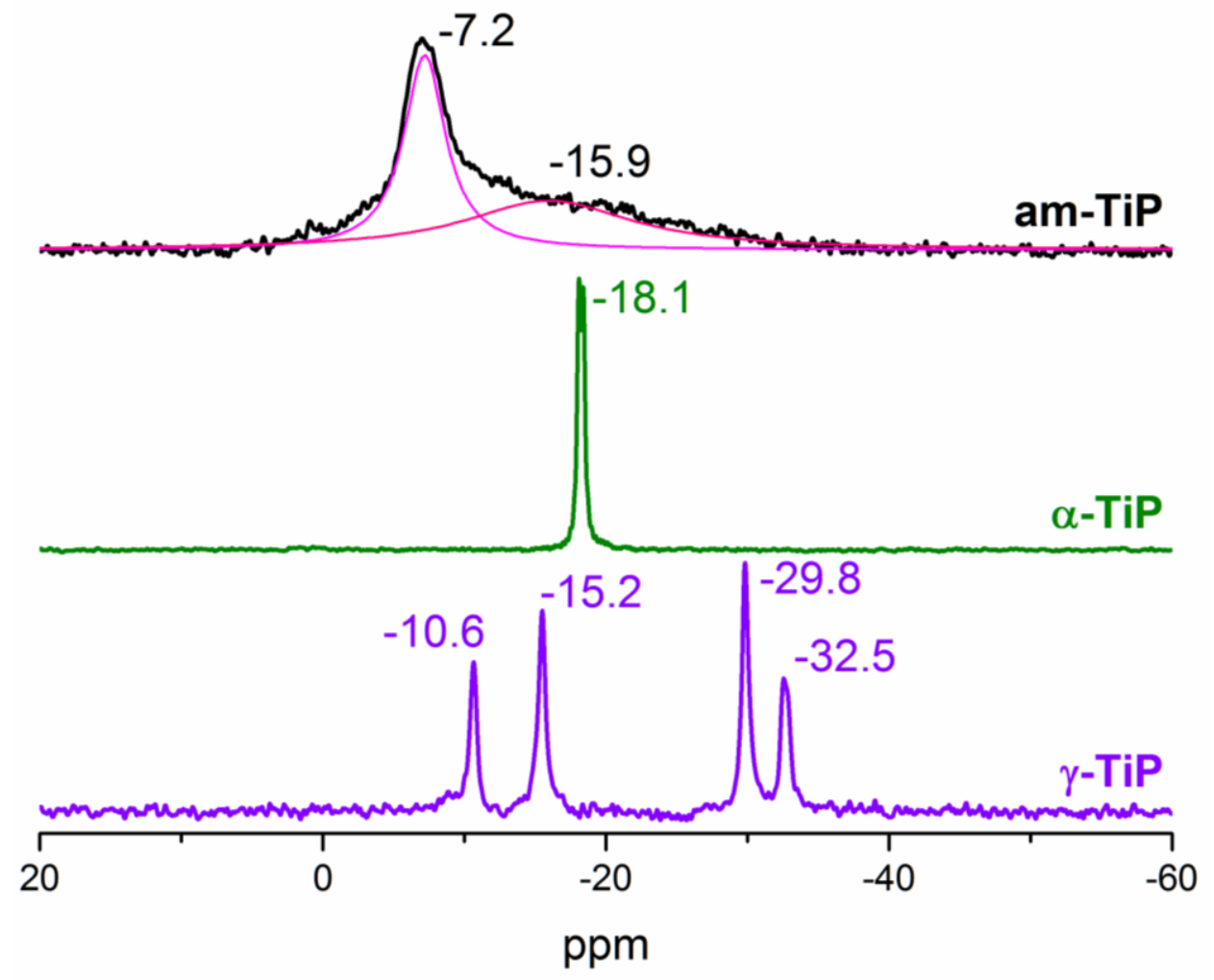

Figure 3. ${ }^{31} \mathrm{P}$ MAS NMR spectra of the TiPs. The line deconvolution was performed on the resonance peak of am-TiP. 

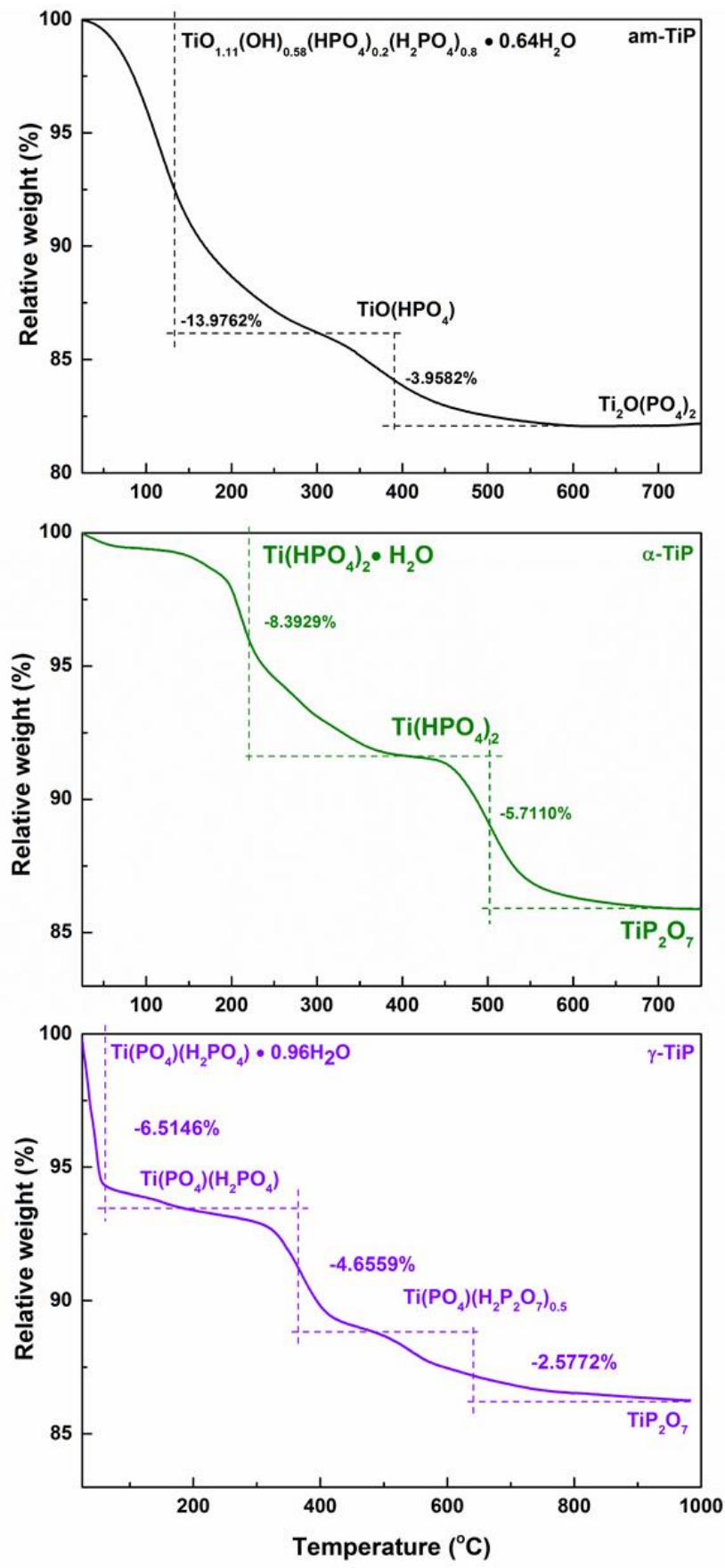

Figure 4. Thermograms of the TiP materials under nitrogen atmosphere at a heating rate of $10{ }^{\circ} \mathrm{C} \mathrm{min}-$ 1. Weight loss stages were derived from first order differential TG curves. 

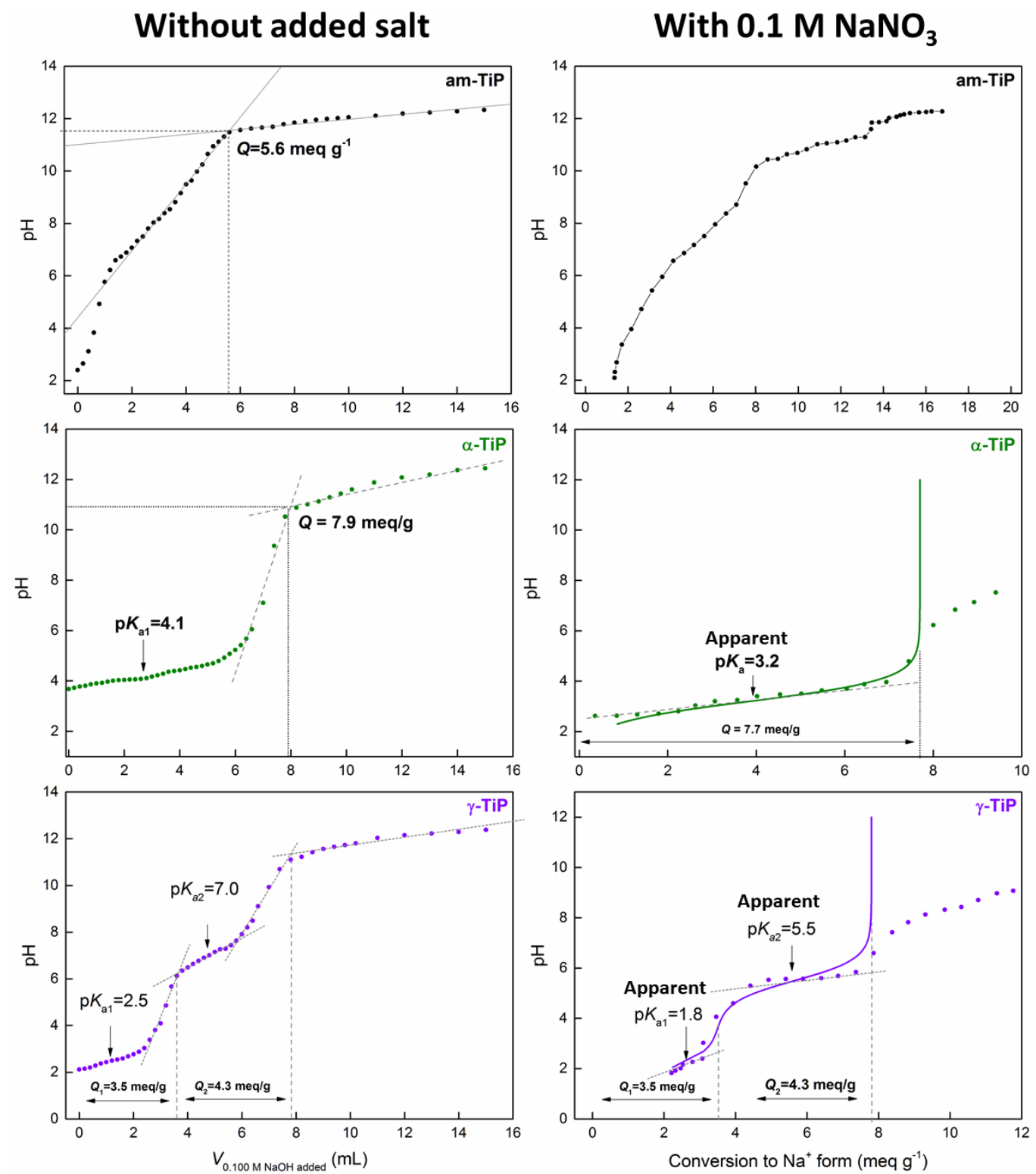

Figure 5. Potentiometric titration curves of the TiPs with (right column) and without added salts (left column). The titration curves (with added salt) of $\alpha$ - and $\gamma$-TiP were simulated used single- and diprotonic acid model. 


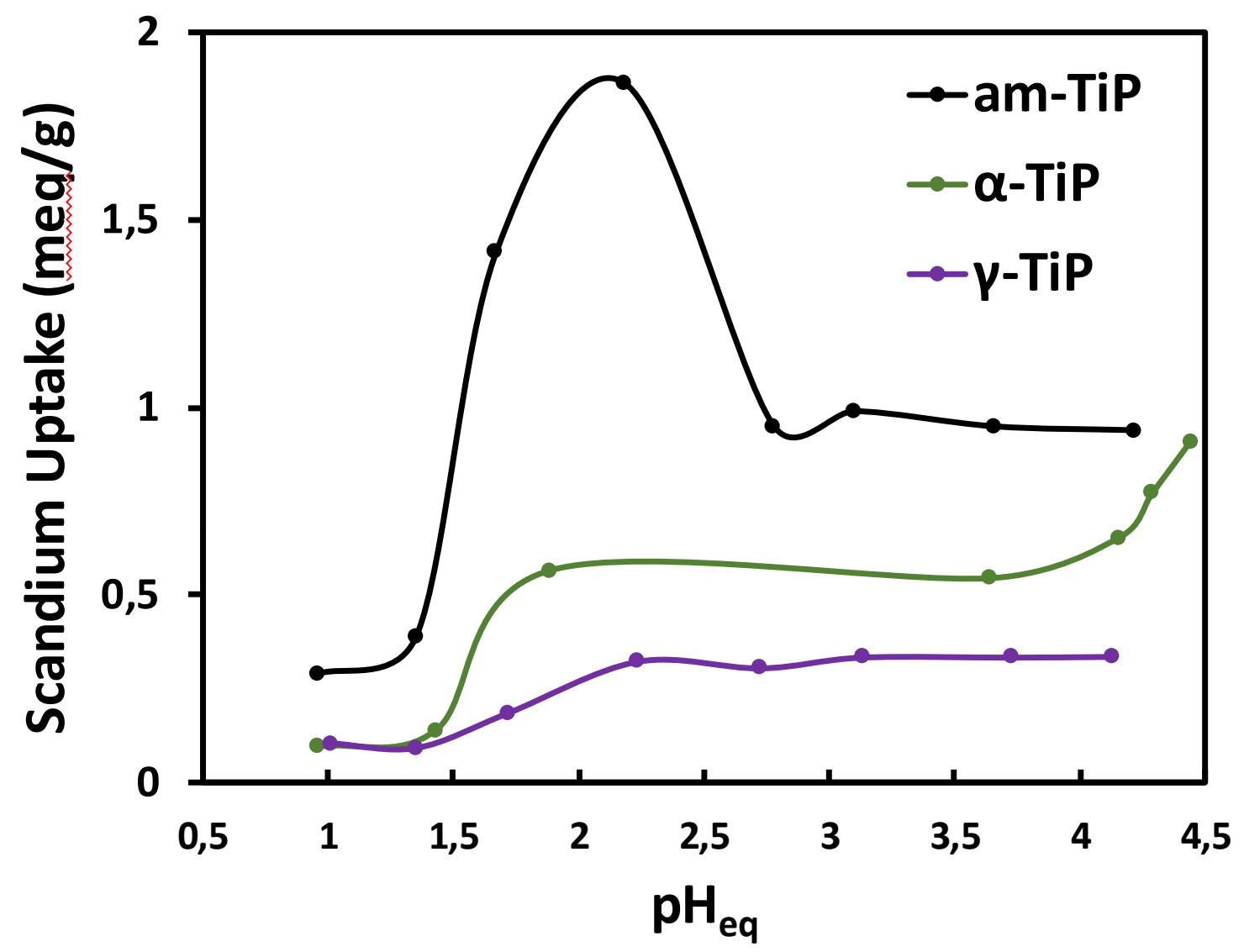

Figure 6. Effects of solution equilibrium pH on Sc uptakes of the TiP materials. 

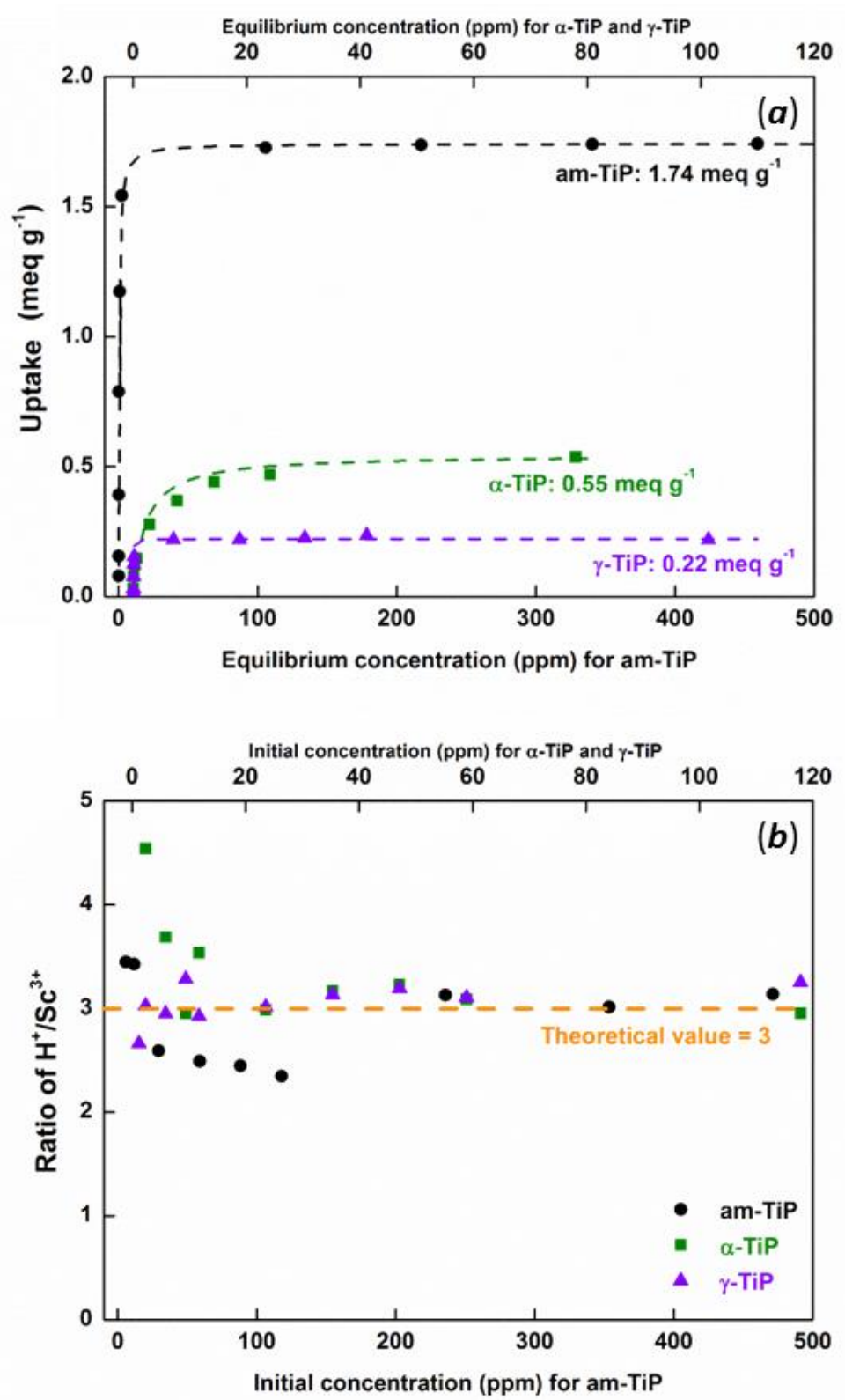

Figure 7. (a) $\mathrm{Sc}^{3+}$ ion exchange isotherms $\left(25^{\circ} \mathrm{C}\right)$ of the TiP materials at equilibrium $\mathrm{pH} 2.0( \pm 0.3)$ and capacities and $(b)$ the corresponding ratios of $\mathrm{H}^{+}$released to $\mathrm{Sc}^{3+}$ adsorbed $\left(\mathrm{H}^{+} / \mathrm{Sc}^{3+}\right)$ as a function of initial $\mathrm{Sc}^{3+}$ concentration. 

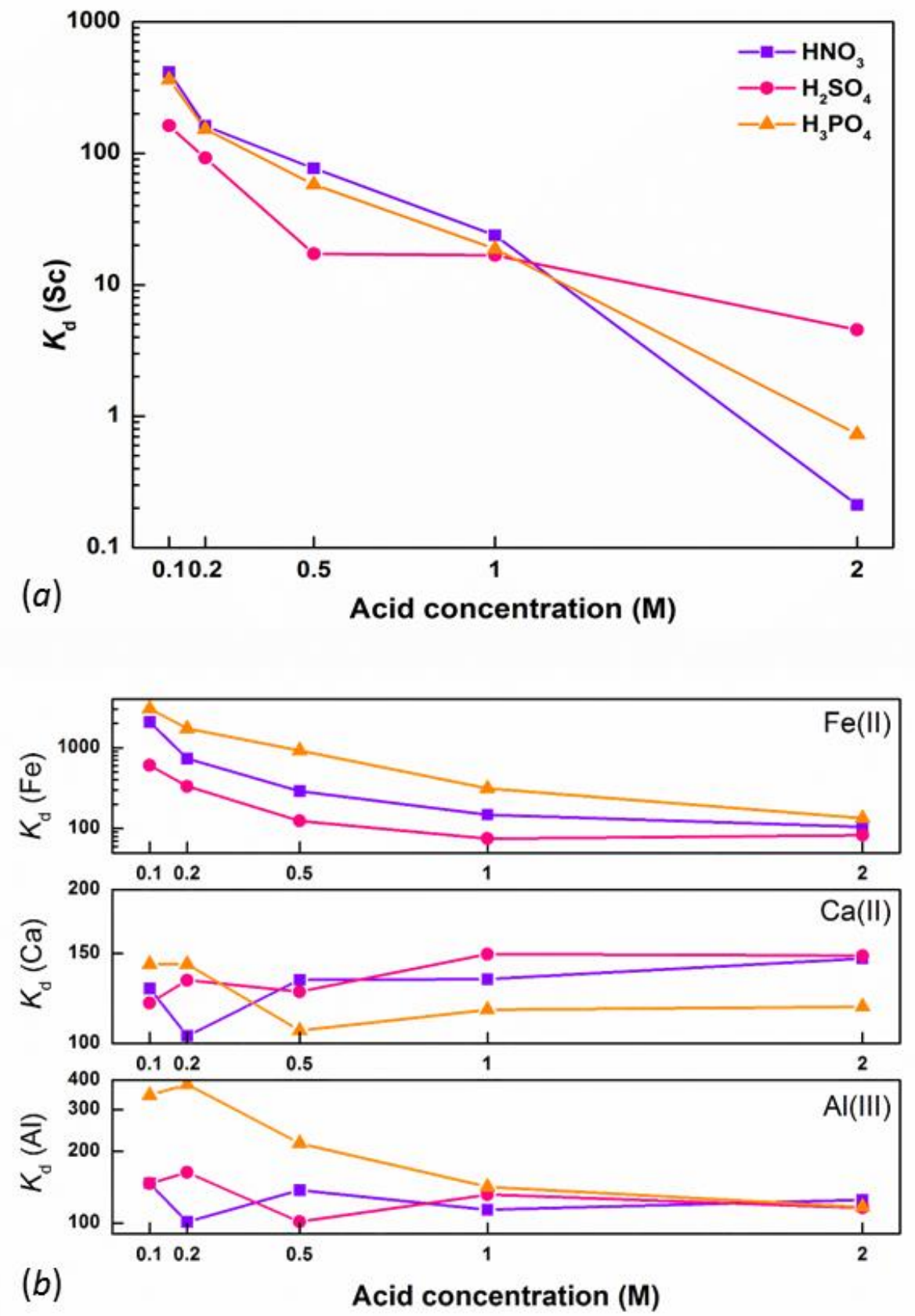

Figure 8. Effects of acid type and concentration on the distribution coefficients $\left(K_{\mathrm{d}}, \mathrm{mL} \mathrm{g}^{-1}\right)$ in batch elution systems: ( $a$ ) Leaching from Sc loaded am-TiP and $(b)$ leaching from Fe(II)/Ca/Al-loaded am-TiP. 

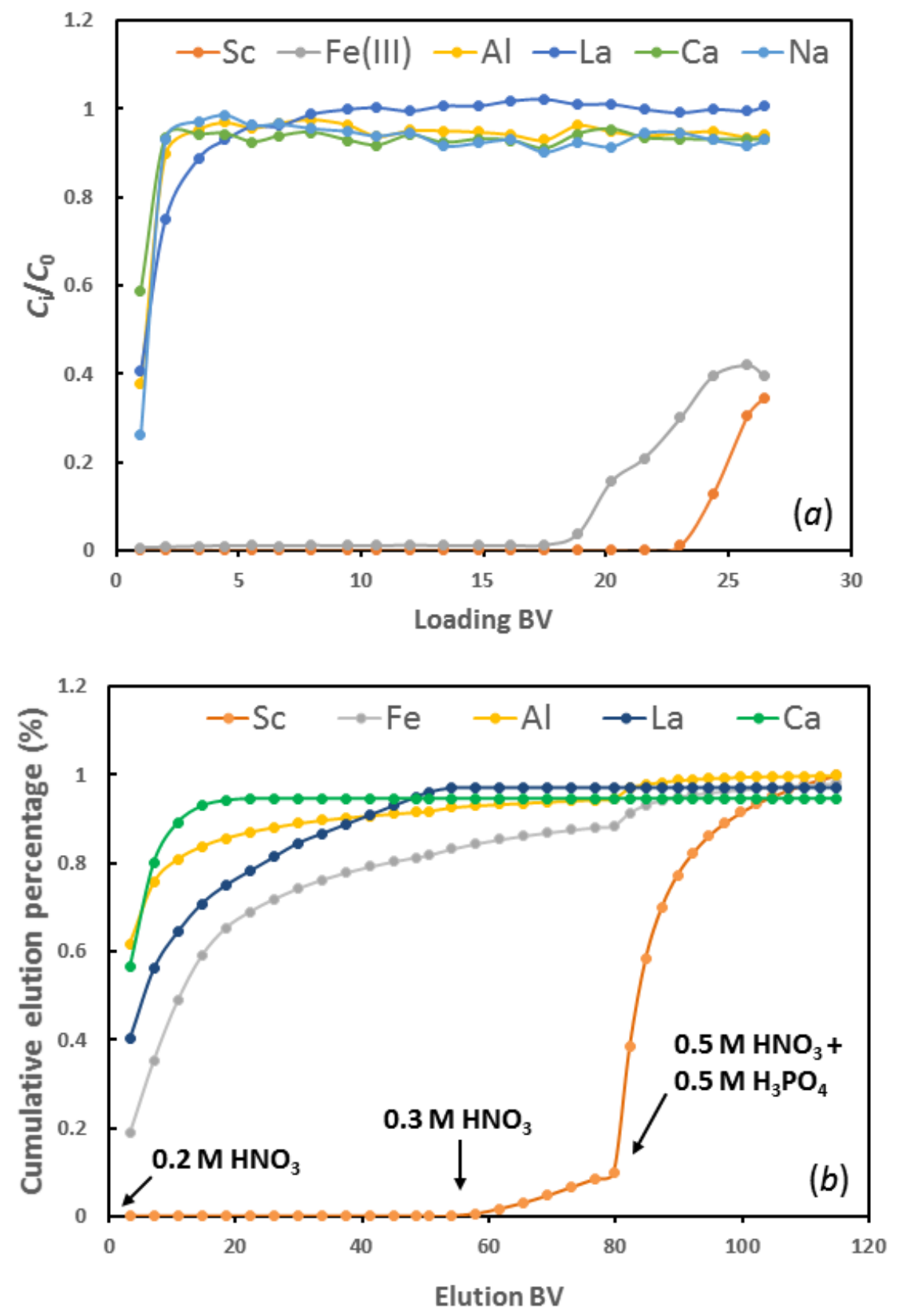

Figure 9. (a) Breakthrough of metal ions in simulated BR leachate at $\mathrm{pH} 2.0$ on am-TiP column and $(b)$ chromatographic elution of simulated BR leachate-load am-TiP column utilizing three different acid solutions. 


\section{Efficient and Selective Recovery of Trace Scandium by Inorganic Titanium Phosphate Ion-Exchangers from Leachates of Waste Bauxite Residue}

Wenzhong Zhang *†, Risto Koivula†, Elmo Wiikinkoski†, Junhua Xu†, Sami Hietalał, Jukka Lehto† and Risto Harjula†

† Laboratory of Radiochemistry, Department of Chemistry, P.O. Box 55, FI-00014 University of Helsinki, Finland

‡ Laboratory of Polymer Chemistry, Department of Chemistry, P.O. Box 55, FI-00014 University of Helsinki, Finland

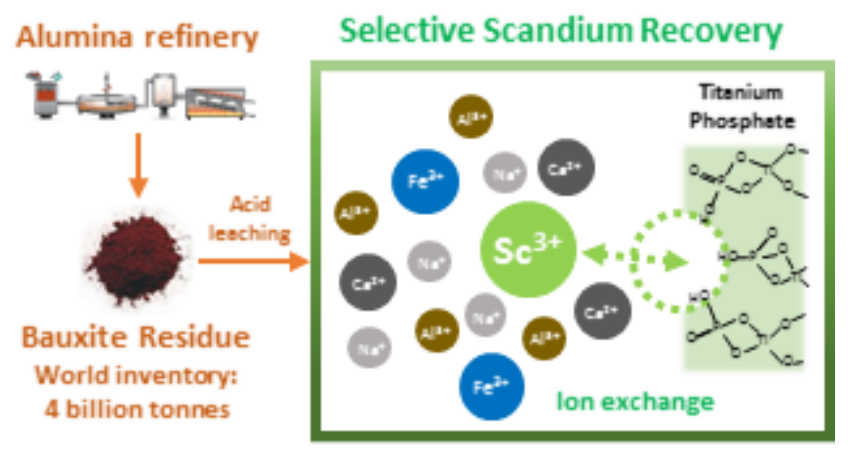

An efficient route to the recovery of trace scandium from complex waste streams by selective ion exchange process. 